\title{
Synthetic and structural studies of 1-halo-8-(alkylchalcogeno)naphthalene derivatives
}

Fergus R. Knight, ${ }^{[\mathrm{a}]}$ Amy L. Fuller ${ }^{[\mathrm{a}]}$ Michael Bühl, ${ }^{[\mathrm{a}]}$ Alexandra M. Z. Slawin ${ }^{[\mathrm{a}]}$ and J. Derek

$$
\text { Woollins*[a] }
$$

[a] Fergus R. Knight, Dr. Amy L. Fuller, Dr. Michael Bühl, Prof. Alexandra M. Z. Slawin, Prof. J. Derek Woollins School of Chemistry, University of St Andrews, St Andrews, Fife, KY16 9ST (UK)

Fax: (+44)1334-463384

E-mail: jdw3@st-and.ac.uk

Series Title and Footnotes: 1-halo-8-(alkylchalcogeno)naphthalene derivatives

Supporting information for this article is available on the WWW under http://dx.doi.org/10.1002/chem.2010xxxxx

\section{Supporting Information Available}

X-ray crystallographic files for $2,4,6-8$

Keywords: naphthalene, peri-substitution, intramolecular, chalcogen, halogen, X-Ray Structure, DFT

INDEX ENTRY: In peri-substituted naphthalenes the non-bonded distance between the halogen and chalcogen is shorter than the sum of van der Waals radii for the two peri-atoms by $12-18 \%$. Is this a bonding or a strained repulsive interaction?<smiles>[X]c1cccc2cccc([X])c12</smiles>

$9 \mathrm{X}=\mathrm{Br}$

$10 X=1$
1. $n$ BuLi (1 equiv), $\mathrm{Et}_{2} \mathrm{O},-78^{\circ} \mathrm{C}, 1 \mathrm{~h}$.<smiles>[X]c1cccc2cccc(Cl)c12</smiles>

2. REER (1 equiv) $\mathrm{Et}_{2} \mathrm{O},-78^{\circ} \mathrm{C}, 1 \mathrm{~h}$.<smiles>[R]c1cccc2cccc([X])c12</smiles>

$1 \mathrm{X}=\mathrm{Br}, \mathrm{ER}=\mathrm{SEt} ; 2 \mathrm{X}=\mathrm{I}, \mathrm{ER}=\mathrm{SEt}$;

$3 \mathrm{X}=\mathrm{Br}, \mathrm{ER}=\mathrm{SPh} ; \mathbf{4 X}=\mathrm{I}, \mathrm{ER}=\mathrm{SPh}$;

$5 \mathrm{X}=\mathrm{Br}, \mathrm{ER}=\mathrm{SePh} ; \mathbf{6} \mathrm{X}=\mathrm{I}, \mathrm{ER}=\mathrm{SePh}$;

$7 \mathrm{X}=\mathrm{Br}, \mathrm{ER}=\mathrm{TePh} ; \mathbf{8 X}=\mathrm{I}, \mathrm{ER}=\mathrm{TePh}$. 


\begin{abstract}
The series of eight 1-halo-8-(alkylchalcogeno)naphthalene derivatives 1-8 (halogen $=\mathrm{Br}, \mathrm{I}, \mathrm{SEt}, \mathrm{SPh}, \mathrm{SePh}, \mathrm{TePh}$ ) containing a halogen and a chalcogen atom occupying the peri-positions have been prepared and fully characterised by X-ray crystallography and multinuclear NMR, IR and MS. Naphthalene distortion due to noncovalent substituent interactions was studied as a function of the bulk of the interacting chalcogen atoms and the size and nature of the alkyl group attached to them. X-ray data for 1, 2, 4, 5-8 were compared. Molecular structures were analysed by naphthalene ring torsions, peri-atom displacement, splay angle magnitude, $\mathrm{X} \cdots \mathrm{E}$ interactions, aromatic ring orientations and quasilinear X $\cdots E-C$ arrangements. A general increase of the X $\cdots E$ distance was observed for molecules containing bulkier

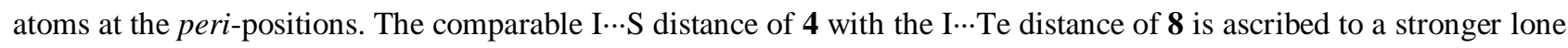
pair-lone pair repulsion due to the presence of an axial S(naphthyl) ring conformation. Density-functional theory (B3LYP) calculations performed on 5-8 revealed Wiberg bond index values of 0.05-0.08 indicating minor interactions taking place between the non-bonded atoms in these compounds.
\end{abstract}

\title{
Introduction
}

Sterically overcrowded systems incorporating bulky heteroatoms at distances shorter than the sum of van der Waals radii have attracted great attention over the last decade. ${ }^{[1]}$ When heteroatoms are confined to unavoidably cramped environments they suffer steric hindrance giving rise to structurally distorted compounds with unusual bonding and geometry. The potential for weak non-covalent interactions to occur between tightly packed heteroatoms is of particular importance. Atomic interactions are a fundamental aspect of chemistry, biology and materials science. ${ }^{[2]}$ Although, great advances have been made in the knowledge of strong covalent and ionic bonding, a major challenge for chemists is to develop a full understanding of weak intra- and intermolecular forces.

The field of peri-substituted naphthalenes has received a large amount attention and has developed to encompass topics such as hypercoordination, hypervalency and three centre-four electron interactions. ${ }^{[1]}$ Peri-substituted naphthalenes are able to constrain heavy polarisable elements in close proximity using a rigid $\mathrm{C}_{2}$-backbone and are therefore ideal models for studying such systems. The distance between the peri-carbon atoms in 'ideal' naphthalene $[2.44 \AA]^{[3]}$ can adequately support two hydrogen atoms, but larger substituents will experience considerable steric hindrance. ${ }^{[4]}$ Repulsive steric effects caused by the crowding of substituents can be overcome by attractive, weak or strong intramolecular bonding, or by distortion of the naphthalene skeleton away from 'ideal' ${ }^{, 4,5]}$ The most common forms of naphthalene distortions are in-plane and out-of-plane deviations of the exocyclic bonds and buckling of the naphthalene ring system. ${ }^{[4]}$

The availability of X-ray structural data plays a crucial role in assessing the repulsive steric effects between heavy perisubstituents and therefore quantifying the distortion in non-ideal naphthalenes. ${ }^{[5]}$ Molecular structures also help to elucidate attractive effects between peri-atoms and verify the existence of weak intra- and intermolecular interactions. To quantify the extent of naphthalene distortion taking place in a given molecule, the naphthalene geometry is compared with that of 'ideal' or un-substituted naphthalene. ${ }^{[3]}$ In-plane distortion is calculated by observing the sum of angles in the bay region; in the 'ideal' geometry of naphthalene these angles sum to $357.2^{\circ} \cdot{ }^{[3]}$ If the splay angle (sum of 
the bay region angles $>360$ ) is positive we can conclude the bonds have moved apart, indicating steric repulsion, but negative splay angles may suggest that the atoms have come closer as a result of favourable interactions. ${ }^{[3,6,7]}$

The distance the peri-substituents reside above and below the naphthalene plane measures out-of-plane distortion; in 'ideal' naphthalene the peri-hydrogens lie on the naphthyl plane. ${ }^{[3]}$ Lastly, torsion angles indicate the planarity of the molecule and give an insight into the degree of buckling taking place in the naphthalene ring system. 'Ideal' naphthalene is totally planar with torsion angles of either $0^{\circ}$ or $180^{\circ} .{ }^{[3,6]}$ The three types of distortion are expressed cumulatively by the value of the peri-distance which is used as the primary parameter when describing the distortion away from 'ideal' and also indicates the presence of peri-atom interaction. ${ }^{[6]}$

Attractive interatomic interactions acting between chalcogen lone-pairs have received attention. ${ }^{[8]}$ Current research in this area utilises the rigid $\mathrm{C}_{3}$-naphthalene backbone to constrain group-16 elements in close proximity and results in a substantial overlap of orbitals. Nakanishi et al. ${ }^{[2,8-12]}$ studied organo-selenium compounds which show typical examples of chalcogen lone-pair lone-pair interactions. At the start of their project they synthesised bis[8(phenylselanyl)naphthyl]-1,1'-diselenide A and 1-(methylselanyl)-8-(phenylselanyl)naphthalene B (Figure 1). ${ }^{\left[{ }^{[]}\right.}$From X-ray crystallography, the molecular structure of $\mathbf{A}$ revealed a quasi-linear arrangement of four selenium atoms. To help rationalize both structures, ab initio $\mathrm{MO}$ calculations were performed. The linear arrangement in $\mathbf{A}$ was reported to arise as the result of an energy lowering effect due to the construction of a four center-six electron bond (4c-6e), ${ }^{[9]}$ whilst the lone-pair interaction taking place in $\mathbf{B}$ suggested a two-center four-electron (2c-4e) interaction. ${ }^{[9]}$<smiles>c1ccc([Se]c2cccc3cccc([Se]c4ccccc4)c23)cc1</smiles>

A<smiles>COc1ccc([Se]c2cccc3cccc(F)c23)cc1</smiles>

C<smiles>C[Se]c1cccc2cccc([Se]c3ccccc3)c12</smiles>

B<smiles>[Y]c1ccc([Se]c2cccc3cccc(Cl)c23)cc1</smiles>

$$
\begin{gathered}
\mathbf{D}(\mathrm{G}=\mathrm{Cl}), \mathbf{E}(\mathrm{G}=\mathrm{Br}), \mathbf{F}(\mathrm{G}=\mathrm{H}), \mathbf{G}(\mathrm{G}=\mathrm{SeMe}) \\
\begin{array}{cccccccc}
\mathbf{a} & \mathbf{b} & \mathbf{c} & \mathbf{d} & \mathbf{e} & \mathbf{f} & \mathbf{g} \\
\hline \mathrm{Y} & =\mathrm{H} & \mathrm{OMe} & \mathrm{Me} & \mathrm{Cl} & \mathrm{Br} & \mathrm{CO}_{2} \mathrm{Me} & \mathrm{NO}_{2}
\end{array}
\end{gathered}
$$

Figure 1 Compounds investigated by Nakanishi et al. ${ }^{[2,8-12]}$

In a subsequent paper Nakanishi and co-workers prepared 8-fluoro-1-(p-anisylselanyl)naphthalene $\mathbf{C}$ (Figure 1). ${ }^{[10]}$ The molecular structure exhibits a linear alignment of the type F...Se-C with an F-Se-C angle of $175.0^{\circ}$. Following ab initio MO calculations the linear arrangement was found to result from a charge-transfer from the fluorine atom to the $\sigma^{*}$ orbital of selenium. ${ }^{[10]}$ 
Expanding their research, Nakanishi et al went on to study the effects of nonbonded G‥Se-C 3c-4e interactions on the structures of a series of compounds with the 8-G-1-(p- $\left.\mathrm{YC}_{6} \mathrm{H}_{4} \mathrm{Se}\right) \mathrm{C}_{10} \mathrm{H}_{6}$ structural motif. Compounds $(\mathbf{D}(\mathrm{G}=\mathrm{Cl}), \mathbf{E}(\mathrm{G}$ $=\mathrm{Br}), \mathbf{F}(\mathrm{G}=\mathrm{H})$ and $\mathbf{G}(\mathrm{G}=\mathrm{H}): \mathrm{Y}) \mathrm{H}(\mathbf{a}), \mathrm{OMe}(\mathbf{b}), \mathrm{Me}(\mathbf{c}), \mathrm{Cl}(\mathbf{d}), \mathrm{Br}(\mathbf{e}), \mathrm{COOEt}(\mathbf{f})$, and NO2 (g)) were synthesised $^{[2,8-12]}$ and X-ray crystal structures were obtained for $\mathbf{D}(\mathbf{b}-\mathbf{d}), \mathbf{E}(\mathbf{d}, \mathbf{g}), \mathbf{H}(\mathbf{a}, \mathbf{b}, \mathbf{d})$ and $\mathbf{G}(\mathbf{a}-\mathbf{f})$. Each structure was classified as either type $\mathrm{A}, \mathrm{B}$ or $\mathrm{C}$ depending upon the position of the $\mathrm{Se}-\mathrm{C}_{\mathrm{Ar}}$ bond relative to the mean naphthalene plane (in type A the $\mathrm{Se}-\mathrm{C}_{\mathrm{Ar}}$ bond lies almost perpendicular to the naphthalene plane, in type $\mathrm{B}$ the bond is located on the plane, the type $\mathrm{C}$ structure is intermediate between type $\mathrm{A}$ and type $\mathrm{B}){ }^{[2,8,9,11]}$

The structures of the members of $\mathbf{D}, \mathbf{E}, \mathbf{F}$ and $\mathbf{G}$ which were not determined by the X-ray crystallographic analysis were estimated from $a b$ initio MO calculations and NMR studies. ${ }^{[2,8-12]}$ Nakanishi et al found that compounds where $\mathrm{G}=\mathrm{Cl}$ or $\mathrm{Br}$ always adopt the type $\mathrm{B}$ structure irrespective of what occupied the $\mathrm{Y}$ position and thus contain the linear nonbonded G...Se-C arrangement. On the basis of ab initio MO calculations they concluded that 'the linear alignment of the three atoms must be the result of the non-bonded $G \cdots S e-C 3 c-4$ e type interaction, ${ }^{[8]}$

We have previously explored sterically crowded 1,8-disubstituted naphthalenes. ${ }^{[13,14]}$ Our early work focussed on dichalcogenide ligands ${ }^{[13]}$ and unusual phosphorus compounds, ${ }^{[14]}$ but we have recently been studying mixed phosphoruschalcogen ${ }^{[15]}$ and chalcogen-chalcogen systems. ${ }^{[16]}$ Positioning large elements such as those of group-16 or -17 in close proximity at the 1,8-positions in naphthalene causes steric compression and provides good systems with which to study naphthalene distortion and the emergence of non-covalent peri-atom interactions.<smiles>[X]c1cccc2cccc([X])c12</smiles>

$$
1 \mathrm{X}=\mathrm{Br}
$$$$
2 X=1
$$<smiles>[X]c1cccc2cccc(S)c12</smiles>

$3 \mathrm{X}=\mathrm{Br}$

$4 X=1$<smiles>[X]c1cccc2cccc([SeH](=O)c3ccccc3)c12</smiles>

$5 \mathrm{X}=\mathrm{Br}$

$6 X=1$<smiles>[X]c1cccc2cccc([Te]c3ccccc3)c12</smiles>

$7 \mathrm{X}=\mathrm{Br}$

$8 X=1$

Figure 2 The products of single substitution reactions of 1,8-dibromo and 1,8-diiodonaphthalene with diphenyl dichalcogenides.

The work presented in this report complements our earlier studies of chalcogen based systems ${ }^{[16]}$ and the work undertaken by Nakanishi et al on $8-\mathrm{G}-1-\left(\mathrm{p}-\mathrm{YC}_{6} \mathrm{H}_{4} \mathrm{Se}\right) \mathrm{C}_{10} \mathrm{H}_{6}$ type compounds. ${ }^{[8]}$ Here we report the synthesis and structural analysis of two compounds adopting this structural motif, along with 6 analogous (sulfur and tellurium) mixed halogen-chalcogen peri-substituted systems 1-8 (Figure 2). 1-8 were prepared via a new synthetic route utilising halogen-lithium exchange reactions of 1,8-dibromonaphthalene $\mathbf{9}$ and 1,8-diiodonaphthalene 10, although $\mathbf{1},{ }^{[17,18]} \mathbf{3}^{[19,20]}$ and $\mathbf{5}^{[8,20,21]}$ have been previously reported; 5 was reported previously by Nakanishi et al and in the same study the chloro analogue $\mathbf{D}(\mathbf{a})$ was synthesised. ${ }^{[8]}$ From $a b$ inito $\mathrm{MO}$ calculations, the chloro and fluoro derivatives were estimated to adopt a similar structure (type B) to that of $5 .{ }^{[8]}$ To the best of our knowledge, the chloro and fluoro analogues of the $\mathrm{SEt}, \mathrm{SPh}$ and $\mathrm{TePh}$ derivatives are unknown.

Here, molecular structures of 1, 2, 4-8 (determined by X-ray crystallography) are compared in terms of molecular distortion in the naphthalene scaffold and the geometry around the chalcogen atom. For each structure, naphthalene ring 
torsion angles, peri-atom displacement, splay angle magnitude, X‥E interactions, aromatic ring orientations and quasilinear C-E $\cdots X$ arrangements were calculated. We have previously published the structures of $\mathbf{1}^{[18]}$ and $\mathbf{5} .^{[21]}$ The structural conformations of $\mathbf{1}, \mathbf{2}, \mathbf{4 - 8}$ have been characterised based on the classification system proposed by Nakanishi et al. $^{[2,8,9,11]}$

\section{Results and Discussion}

Compounds 1-8 were synthesised and crystal structures were determined for 1, 2, 4-8. Apart from the previously reported compounds $\left(\mathbf{1}^{[17]}\right.$ and $\left.\mathbf{5}^{[8]}\right)$, all the derivatives were spectrally characterised by multinuclear NMR and IR spectroscopy and mass spectrometry and the homogeneity of the new compounds was, where possible, confirmed by microanalysis.

The series of 1-halo-8-(alkylchalcogeno)naphthalene derivatives 1-8 were prepared from a new synthetic route utilising the stepwise halogen-lithium exchange reactions of analogous 1,8-dibromonaphthalene $\mathbf{9}^{[22]}$ and 1,8-diiodonaphthalene $\mathbf{1 0}^{[23]}$ as shown in Scheme 1. For their synthesis, $\mathbf{9}$ and $\mathbf{1 0}$ were independently treated with a single equivalent of $n$ butyllithium in diethyl ether, substituting one of the halogen atoms to afford the respective 1-halo-8-lithionaphthalene precursor. The addition of a suitable dichalcogenide (diethyl disulfide, diphenyl disulfide, diphenyl diselenide and diphenyl ditelluride) to the reaction mixture consequently afforded the series of compounds 1-8 [43\% 1, $42 \% \mathbf{2}, 51 \%$ $\mathbf{3}, 26 \% \mathbf{4}, 63 \% \mathbf{5}, 60 \% \mathbf{6}, 32 \% \mathbf{7}, 18 \% \mathbf{8}$ ] (Scheme 1).
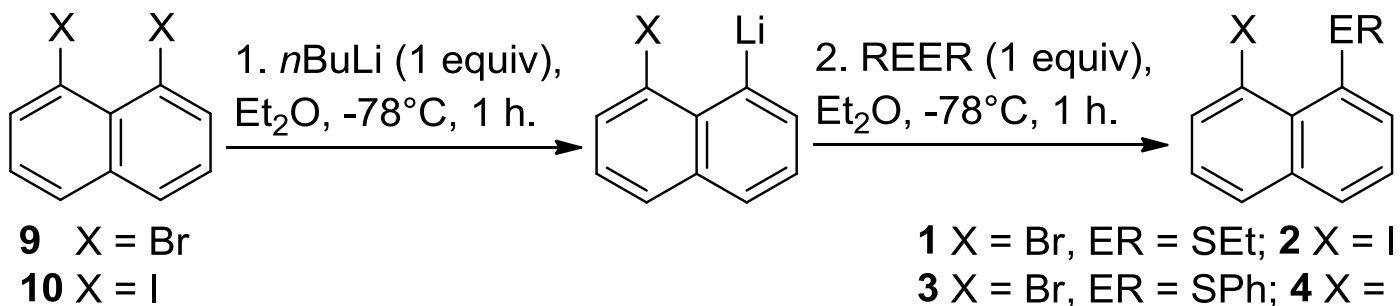

$$
\begin{aligned}
& 1 \mathrm{X}=\mathrm{Br}, \mathrm{ER}=\mathrm{SEt} ; \mathbf{2} \mathrm{X}=\mathrm{I}, \mathrm{ER}=\mathrm{SEt} \\
& \mathbf{3 X}=\mathrm{Br}, \mathrm{ER}=\mathrm{SPh} ; \mathbf{4}=\mathrm{I}, \mathrm{ER}=\mathrm{SPh} \\
& \mathbf{5 X}=\mathrm{Br}, \mathrm{ER}=\mathrm{SePh} ; \mathbf{6}=\mathrm{I}, \mathrm{ER}=\mathrm{SePh} ; \\
& \mathbf{7 X}=\mathrm{Br}, \mathrm{ER}=\mathrm{TePh} ; \mathbf{8} \mathrm{X}=\mathrm{I}, \mathrm{ER}=\mathrm{TePh} .
\end{aligned}
$$

Scheme 1 The preparation of 1-halo-8-(alkylchalcogeno)naphthalenes 1-8.

1-8 were characterised by elemental analysis, infra red spectroscopy, ${ }^{1} \mathrm{H}$ and ${ }^{13} \mathrm{C}$ NMR spectroscopy and mass spectrometry. 5 and $\mathbf{6}$ were analysed by ${ }^{77} \mathrm{Se}$ NMR spectroscopy [ $\left.5 \delta=447.8 ; \mathbf{6} \delta=430.8 \mathrm{ppm}\right]$ and $\mathbf{7}$ and $\mathbf{8}$ were analysed by ${ }^{125} \mathrm{Te}$ NMR spectroscopy [ $\mathbf{7} \delta=731.23 \mathrm{ppm} ; \delta=698.26 \mathrm{ppm}$ ]. Characterisation for $\mathbf{1}$ and $\mathbf{5}$ was found to be in accord with the literature. ${ }^{[8,17]}$

\section{X-ray investigations}

Suitable single crystals were obtained for 1, 2, 4-8 by diffusion of pentane into saturated solutions of the individual compound in dichloromethane. Compound $\mathbf{3}$ was found to occur as an oil at room temperature. The molecular structures of 1, 2, 4-8 are analysed together here, though $\mathbf{1}^{[18]}$ and $\mathbf{5}^{[21]}$ have been previously reported by us. Compounds $\mathbf{2 , 4 - 8}$ crystallise with one molecule in the asymmetric unit, compound 1 contains two nearly identical molecules in the asymmetric unit. Figures 5-8 show the structures of 2, 4, $\mathbf{6}$ and 7-8 respectively. Selected interatomic distances, angles 
and torsion angles are listed in Table 1. Further crystallographic information can be found in Table 4 and the Supporting Information.

The substitution of large halogen and chalcogen atoms in the 1,8-positions of derivatives 1-8 imposes a great amount of steric strain between the peri-atoms. The subsequent displacement of the peri-atoms within and away from the naphthalene plane is accompanied by a significant buckling of the naturally planar naphthalene skeleton and assists in alleviating the strain. The distortion observed correlates to the bulk of the two interacting atoms in the naphthalene molecule as indicated by the primary parameter for naphthalene distortion, the peri-distance. The structures of $\mathbf{1 , 2}, \mathbf{4 - 8}$, reveal the halogen atom lies in close proximity to the E(alkyl) group in all cases, with non-bonded interatomic peridistances $(\mathrm{X} \cdots \mathrm{E})$ displaying a general increase when larger atoms occupy the close contact 1,8-positions (see Table 1, Figure 3). The $\mathrm{X} \cdots \mathrm{E}$ distances [3.06-3.34 $\AA$ ] are less than the respective sum of van der Waals radii for the two interacting atoms $[3.65-4.04 \AA]^{[24]}$ and in all derivatives this distance is between 82 and $88 \%$ of the vdW sum (Table 1). ${ }^{[24]}$ These short non-bonded peri-distances indicate the possible existence of weak intramolecular interactions. ${ }^{[25]}$

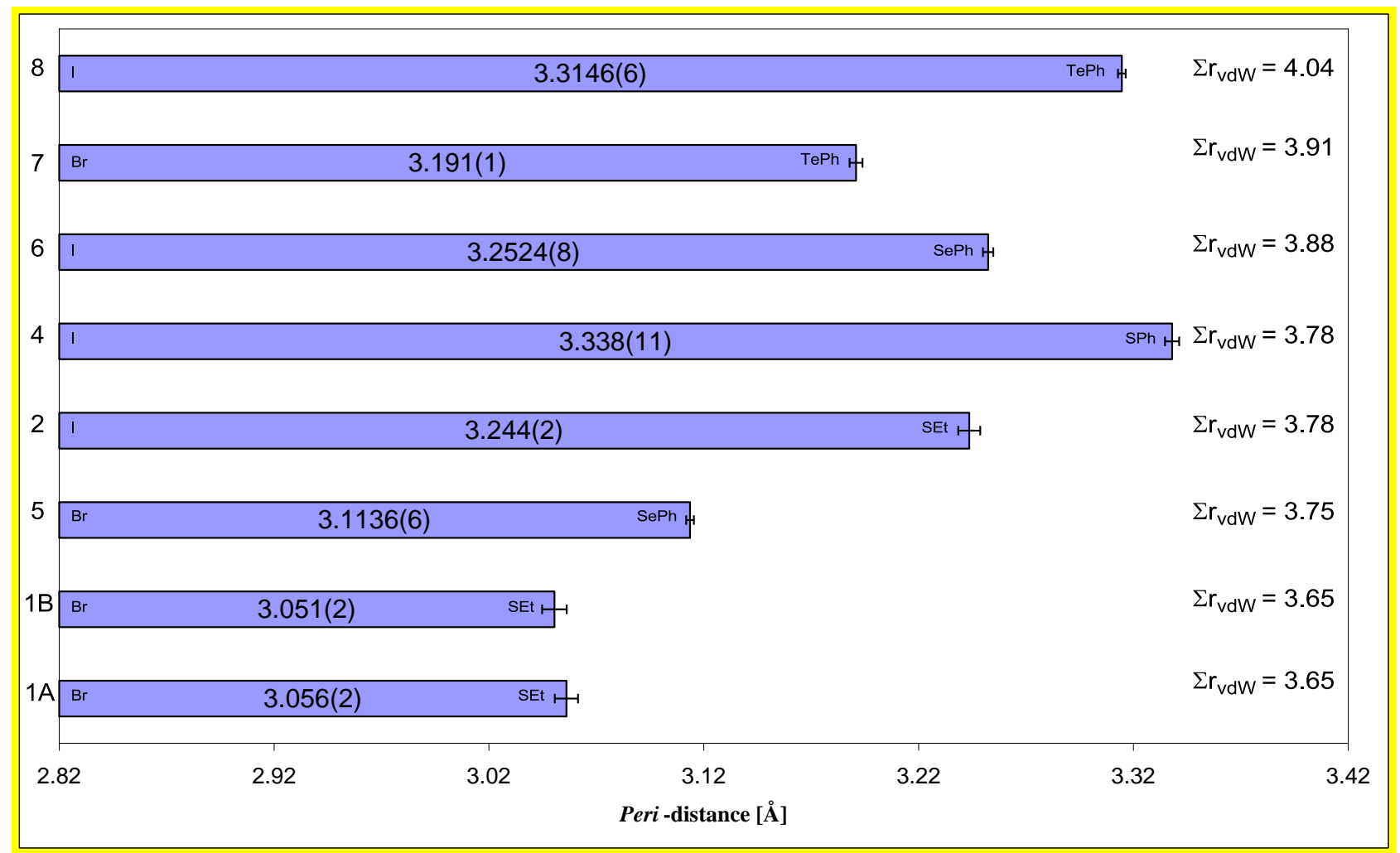

Figure 3 Peri-distances for Nap[X][ER] derivatives 1-8.

Bond lengths around C10, closer to the repulsive interactions, are on average longer than those around C5 [average 1.44 $\AA ̊ 2$ and $1.42 \AA$ respectively] and C(1)-C(10)-C(9) bond angles splay to a mean $129^{\circ}$, away from the 'ideal' geometry as observed for $\mathrm{C}(4)-\mathrm{C}(5)-\mathrm{C}(6)$ (average $\left.119^{\circ}\right) .{ }^{[3]}$ The aforementioned bond stretching and angle widening distortions are insufficient enough alone to overcome the steric strain between the peri-atoms. Supplementary widening of the E(1)$\mathrm{C}(1)-\mathrm{C}(10)$ and $\mathrm{E}(2)-\mathrm{C}(9)-\mathrm{C}(10)$ angles and displacement of the peri-atoms from the mean naphthyl plane takes place to aid the alleviation of steric pressure. 
The halogen and chalcogen atoms are displaced to different sides of the naphthalene least-squares plane in all seven derivatives. The distortion from this plane ranges from $0.01 \AA$ to $0.54 \AA$. The least amount of steric strain is observed in $\mathbf{1}$, as indicated by the relatively little displacement of the bromine and sulfur atoms $\left[\Sigma \mathrm{r}_{\mathrm{vdW}}=3.65 \AA\right]^{[24]}$ from the naphthyl plane by $-0.14 \AA(0.01 \AA)$ and $0.04 \AA$ (-0.04 $\AA$ ) (Figure 4). Out-of-plane distortion is observed to the greatest extent in $\mathbf{8}$ where the displacement of the large iodine and tellurium atoms $\left[\Sigma r_{v d W}=4.04 \AA\right]^{[24]}$ is $-0.42 \AA$ and $0.54 \AA$ respectively (Figure 4). The positive splay angles of the seven derivatives [13.0-20.8 ${ }^{\circ}$ indicate considerable distortion has taken place in the bay area within the naphthyl plane. The X-C and E-C bonds are forced apart minimising the steric repulsion between the two bulky atoms and alleviate "perispace crowding". [26]

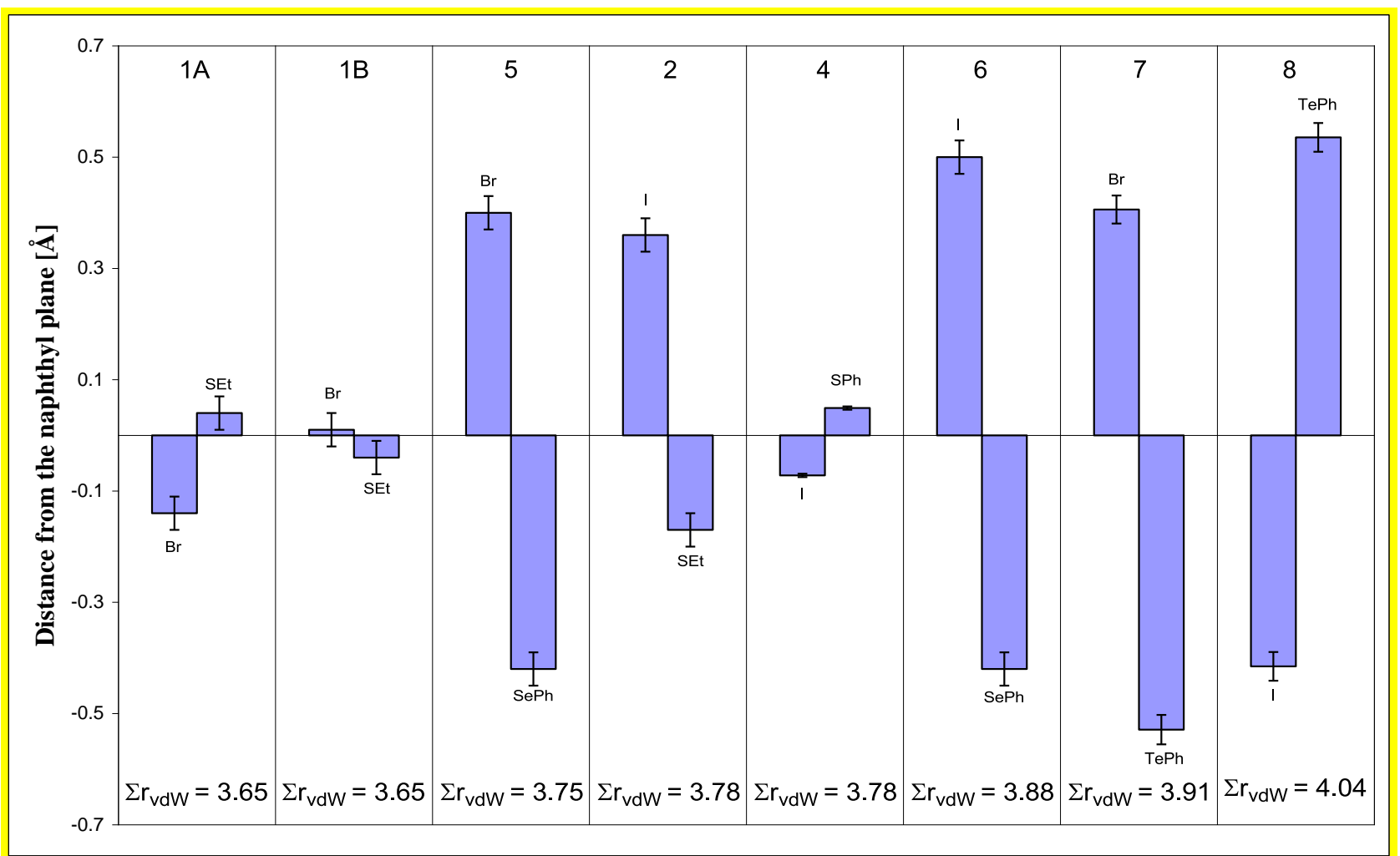

Figure 4 Out-of-plane displacement of the peri-atoms to oppotsite sides of the naphthalene mean plane in the

\section{Nap[X][ER] derivatives $\mathbf{1 - 8}$.}

The conformation and arrangement of the $\mathrm{E}($ naphthyl) and $\mathrm{E}($ phenyl) rings, relative to the $\mathrm{C}(\mathrm{ar})-\mathrm{E}(1)-\mathrm{C}(\mathrm{ar}) \mathrm{plane}$, can be categorised from torsion angles $\theta$ and $\gamma$ respectively (see Table 2). When $\theta$ and $\gamma$ approach $90^{\circ}$ the orientation is denoted axial and when the angles indicate a quasi-planar arrangement (close to $180^{\circ}$ ), they are termed equatorial. ${ }^{[27]}$

Derivatives $\mathbf{1}$ and $\mathbf{2}$ display an equatorial-equatorial conformation of the naphthyl ring and ethyl group around the sulfur atom with respect to the $\mathrm{C}(\mathrm{Nap})-\mathrm{E}-\mathrm{C}(\mathrm{Et})$ plane. The increased congestion in the peri-region of 2 , results in a larger displacement of the peri-atoms to opposite sides of the naphthalene least-squares plane compared to 1 [ $1-0.14 \AA(0.01$ $\AA$ ) and $0.04 \AA(-0.04 \AA) ;{ }^{[18]} 20.36 \AA$ and $\left.-0.17 \AA\right]$. Considerable distortion of the bay-region geometry within the naphthyl plane is observed in both compounds, but there is little difference between the splay angles $\left[14.5^{\circ}\left(15.1^{\circ}\right)\right.$ for $\mathbf{1} ;{ }^{[18]} 16.9^{\circ}$ for 2]. The X-C and S-C bonds are tilted in opposite directions, minimising steric repulsion between the heavy atoms and alleviating 'perispace crowding'. ${ }^{[26]}$ The deviation of the central naphthalene ring torsion angles from planarity is more pronounced in $\mathbf{2}\left[\mathrm{ca} 2-3^{\circ}\right]$ compared to $\mathbf{1}$. 


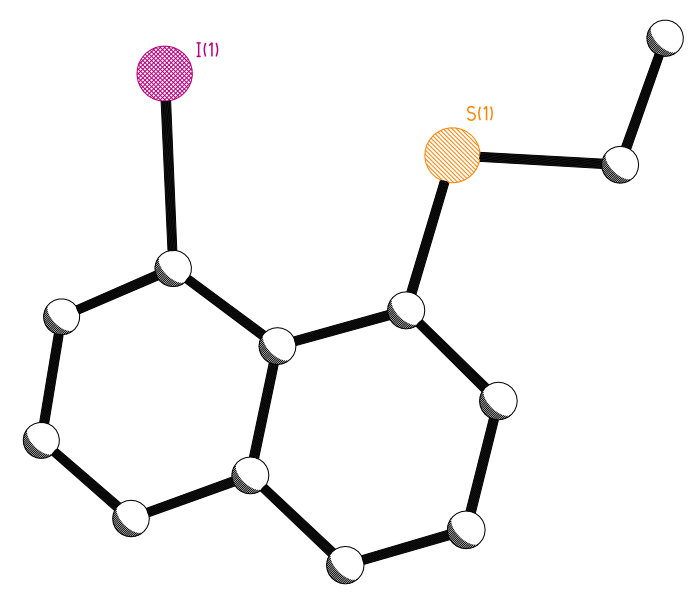

Figure 5 The crystal structure of 1-iodo-8-(ethylsulfanyl)naphthalene 2.

No major distortion of the naphthalene scaffold is observed in $\mathbf{1}$ with the maximum C-C-C-C torsion angle $1.6^{\circ}$ for

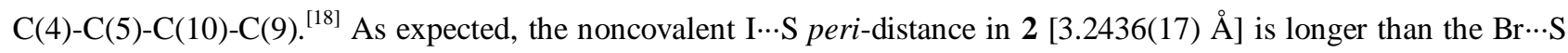
distance in 1 [3.0561(18) $\AA$ (3.050(2) $\AA$ ) 1]. ${ }^{[18]}$ This distance is shorter than the sum of van der Waals radii for the interacting atoms by $0.59 \AA(0.60 \AA)$ and $0.54 \AA$ respectively. ${ }^{[24]} \mathrm{Br}-\mathrm{C}[1.90 \AA]$, I-C [2.13 $\left.\mathrm{A}\right]$ and S-C [1.77-1.78 $\left.\mathrm{A}\right]$ bond lengths are within the usual ranges $[1.90,2.10,1.77 \pm 0.05 \AA]^{[28]}$ in both derivatives. The molecules of $\mathbf{1}$ pack in a herringbone array with no significant $\pi-\pi$ interactions. The shortest intermolecular S $\cdots \mathrm{S}$ distance is $4.199(2) \AA$ and there is a weak intermolecular $\mathrm{C}-\mathrm{H} \cdots \mathrm{Br}$ interaction [for $\mathrm{C}(22)-\mathrm{H}(22 \mathrm{a}) \cdots \mathrm{Br}(1): \mathrm{H} \cdots \mathrm{Br}=3.025 \AA$, $\left.\mathrm{C}-\mathrm{H} \cdots \mathrm{Br}=167^{\circ}\right]^{[18]}$ No significant $\pi-\pi$ interactions are observed in the packing structure of 2 but a short intermolecular $\mathrm{I}(1) \cdots \mathrm{S}(1 \mathrm{~A})$ interaction exists [3.504(1) ̊̊].

The number, size and nature of atoms or groups attached to the peri-atoms of 1,8-disubstituted naphthalenes has an important influence on the extent of steric strain which ultimately dictates the molecular geometry. The disparity between the electronic and steric affects of S(ethyl) and S(phenyl) moieties in derivatives $\mathbf{2}$ and $\mathbf{4}$ results in dissimilar intramolecular interactions, naphthalene distortion and structural arrangements. The S(phenyl) derivative $\mathbf{4}$ arranges with a mixed axial-equatorial conformation of naphthyl and phenyl rings respectively.

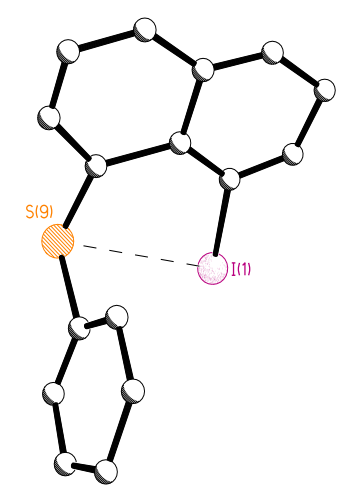

Figure 6 The crystal structure of 1-iodo-8-(phenylsulfanyl)naphthalene 4.

Although considerable distortion within the naphthyl plane occurs in both compounds, the splay of the X-C and E-C bonds is more pronounced in $\mathbf{4}$ to accommodate the larger substituent $\left[216.9^{\circ}, \mathbf{4} 20.8^{\circ}\right]$. Subsequently the non-bonded 


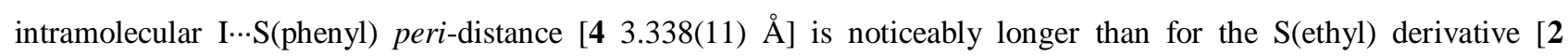
3.2436(17) $\mathrm{A}]$, but still shorter than the sum of van der Waals radii by $0.44 \AA^{\left[{ }^{[24]}\right.}$ The peri-atoms essentially lie on the naphthyl plane in 4, with only a minor displacement observed [-0.07 $\AA$ \& $0.05 \AA$. Naphthalene skeletons for the two derivatives show similar deviations from planarity with central naphthalene ring torsion angles $c a$. $2-3^{\circ}$. I-C [2.12 $\left.\mathrm{A}\right]$ and S-C $[1.77 \AA]$ bond lengths in 4 are within the usual ranges [2.10, $1.77 \pm 0.05 \AA] .{ }^{[28]}$ Although intermolecular short contacts exist, there is no significant overlap of phenyl or naphthalene rings and no $\pi$-stacking in the molecular structure of 4 .

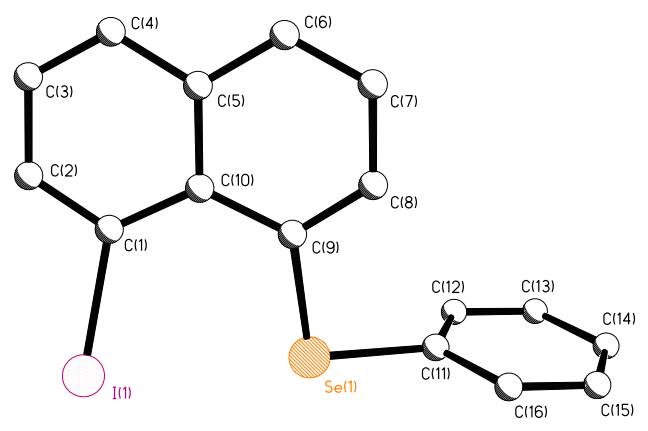

Figure 7 The molecular structure of 1-iodo-8-(phenylselanyl)naphthalene 6.

The increasing magnitude of the peri-atoms [BrSe $3.75 \AA$, ISe $3.88 \AA$, BrTe $3.91 \AA$, ITe $4.04 \AA]^{[24]}$ in derivatives 5-8 causes an escalating degree of steric congestion in the bay region. Steric strain resulting from repulsive $\mathrm{X} \cdots \mathrm{E}$ interactions transpires, forcing the naphthalene geometry to distort further from 'ideal' ${ }^{[3]}$ Non-bonded interatomic peri-

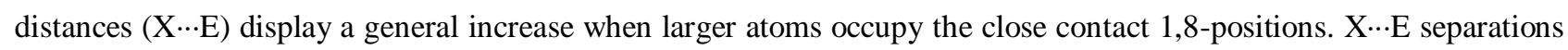

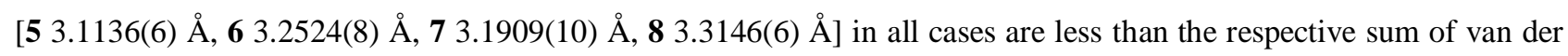
Waals radii for the two interacting atoms; for each distance this is between 82 and $84 \%$ of the vdW sum (Table 1). The increase in steric congestion is accompanied by a larger positive splay of the $\mathrm{X}-\mathrm{C}$ and $\mathrm{E}-\mathrm{C}$ bonds within the naphthyl plane with angles increasing from $13.0^{\circ}(\mathbf{5})$ to $16.2^{\circ}(\mathbf{8})$.
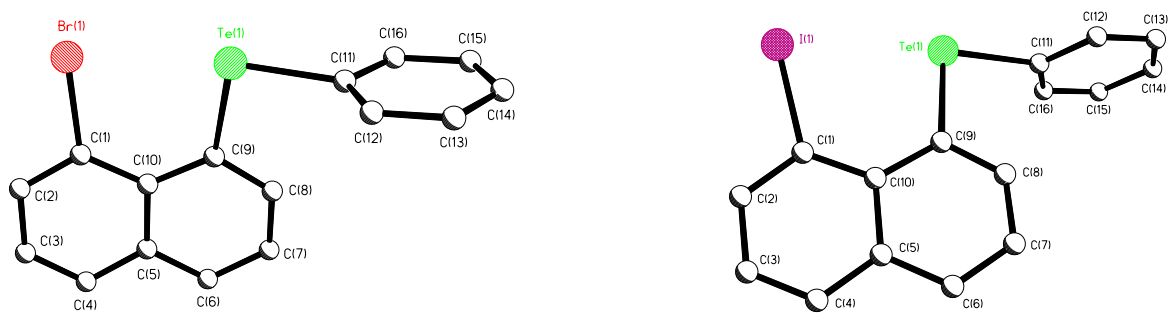

Figure 8 The molecular structure of 1-bromo-8-(phenyltelluro)naphthalene 7 and 1-iodo-8-(phenyltelluro)naphthalene

8.

Displacement of the halogen and chalcogen atoms from the naphthalene best plane however, is comparable for all four derivatives with distances from the plane in the range of 0.40-0.54 $\AA$. The naphthalene unit in each derivative displays considerable buckling with a similar deviation from planarity observed through out the series; central naphthalene ring

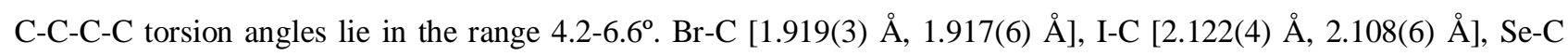

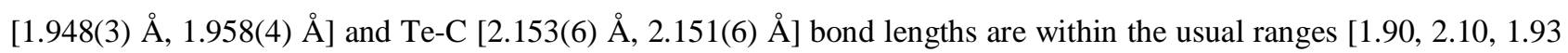


and $2.12 \pm 0.05 \AA$ respectively] ${ }^{[28]}$ in all four compounds. Similar packing is observed throughout the series with expected intermolecular short contacts. There is no significant overlap of phenyl or naphthyl rings and no $\pi-\pi$ stacking.

The analogues 5-8 display a different geometry compared with $\mathbf{4}$, adopting a mixed equatorial-axial conformation of naphthyl and phenyl rings respectively in each case (Table 2). The difference between the two conformations is illustrated by Figure 9 which views the geometrical arrangements down the E(1)-C(9) bond; axial naphthalene conformation in $\mathbf{4}$ and equatorial naphthalene conformation in 5-8.

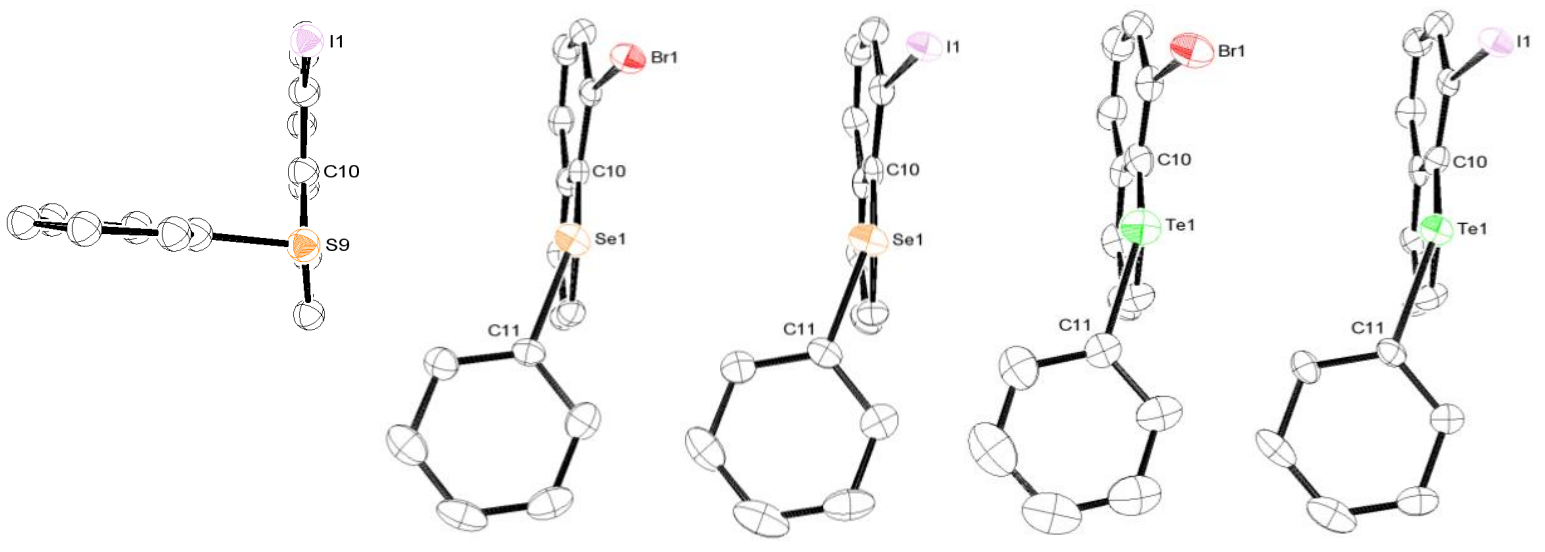

Figure 9 The crystal structures of 4, 5-8 viewed down the E(1)-C(9) bond showing the difference in naphthyl and phenyl ring conformations.

Steric strain operating between the peri-atoms in 4, 5-8 is dominated by the repulsion of p-type lone-pairs, which therefore have a big influence on non-bonded X $\cdots E$ E distances. Compared with derivatives 5-8, compound 4 experiences a larger than expected amount of steric strain as illustrated by a peri-distance [3.338(11) ̊ 4] significantly larger than the $\mathrm{S}$ (ethyl) analogue $\mathbf{2}$ [3.0561(18) $\AA$ ] and comparable to $\mathbf{8}$ [3.3146(6) $\AA$ ] containing much larger iodine and tellurium atoms. The extent of steric strain occurring in $\mathbf{4}$ can be explained by the axial conformation of the E(naphthyl) ring. When torsion angles $\theta$ (see Table 2) approach $90^{\circ}$, the axis of the p-orbitals of the chalcogen atom lie in the plane of the aromatic system and repulsion is relatively high. ${ }^{[27]}$ Conversely, for 5-8, torsion angles $\theta$ approach $180^{\circ}$ (E(naphthyl) conformation being equatorial), the p-orbitals are arranged parallel and vertical to the aromatic plane and less lone pairlone pair repulsion is observed. ${ }^{[27]}$

The possibility of attractive non-covalent $X \cdots E$ interactions occurring in 5-8 is heightened by the presence of a quasi-

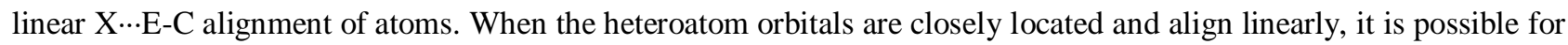
promotion of a halogen lone-pair into the antibonding $\sigma^{*}(\mathrm{E}-\mathrm{C})$ orbital ${ }^{[29]}$ to form a weak unsymmetrical hypervalent interaction. This attractive $\sigma$-type $(\mathrm{X}) \cdots \sigma^{*}(\mathrm{E}-\mathrm{C})$ alignment is known as a three center-four electron (3c-4e) interaction and can influence the conformation of the molecule. . $2,8,-12,30,31]^{-1}$ 


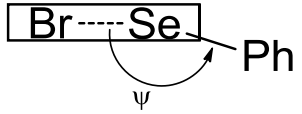

5

type B

$\psi=175.7^{\circ}$

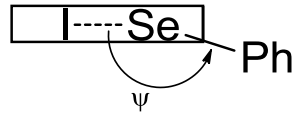

6

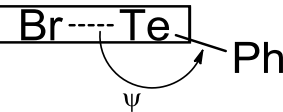

7 type B

$\psi=173.1^{\circ}$

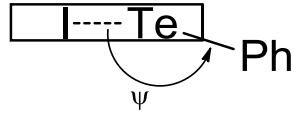

8

$\psi=174.3^{\circ}$

type B

$\psi=175.1^{\circ}$

Figure 10 The orientation of the E(phenyl) groups and type of structure of 5-8 and the quasi-linear arrangements. $^{[2,8,9,11]}$

Nakanishi et al have investigated non-bonded intramolecular interactions in a series of sterically crowded naphthalenes containing the 8-G-1- $\left(p-\mathrm{YC}_{6} \mathrm{H}_{4} \mathrm{Se}\right) \mathrm{C}_{10} \mathrm{H}_{6}$ structural motif. ${ }^{[2,8-12]}$ Compounds where $\mathrm{G}=\mathrm{Cl}$ or $\mathrm{Br}$ (such as 5) were found to adopt 'type B' structures (Se-C bond is located on the naphthyl plane) irrespective of what occupies the $\mathrm{Y}$ position and the linear non-bonded $\mathrm{G} \cdots \mathrm{Se}-\mathrm{C}$ arrangement was concluded to result from the occurrence of a $3 \mathrm{c}-4 \mathrm{e}$ bond. ${ }^{[2,8,-12,30,31]}$

Derivatives 6-8 also adopt the 'type B' structure with E-C bonds lying close to the naphthalene plane (Figure 10). The $\mathrm{E}$ (phenyl) moieties sit in similar locations in all four derivatives and produce a quasi-linear arrangement of the type X $\cdots$ E-C with angles approaching $180^{\circ}\left[5 \mathrm{Br} \cdots \mathrm{Se}-\mathrm{C} 175.7^{\circ}, 6 \mathrm{I} \cdots \mathrm{Se}-\mathrm{C} 174.3^{\circ}, 7 \mathrm{Br} \cdots \mathrm{Te}-\mathrm{C} 173.1^{\circ}, 8 \mathrm{I} \cdots \mathrm{Te}-\mathrm{C} 175.1^{\circ}\right.$ ] (Figure 10).

To try and assess the possibility of direct $\mathrm{X} \cdots \mathrm{E}$ bonding interactions that would indicate an onset of $3 \mathrm{c}-4 \mathrm{e}$ bonding, density functional theory computations were performed for derivatives 5-8 at the B3LYP/6-31+G* level. The Wiberg bond index (WBI), ${ }^{[32]}$ which measures the covalent bond order, was calculated and increased from 0.05 for $\mathbf{5}$ to 0.08 for $\mathbf{8}$, but indicates a very minor interaction taking place between the non-bonded atoms in these compounds (Table 3). For comparison, the fully covalent S-S single bond in naphtho(1,8-cd)(1,2-dithiole) has a WBI of 0.99 at the same level.

These results illustrate that more pronounced interactions could be expected as the neighbouring atoms become larger. Even stronger interactions can occur when one of the Se atoms carries an acceptor and indeed, when the "equatorial" $\mathrm{Ph}$ group on Se1 in 1,8-bis(phenylselanyl)naphthalene is replaced with $\mathrm{Br}$, Se-Se distances as short as $2.516 \AA$ have been observed ${ }^{[33]}$ A B3LYP computation for the latter molecule from the X-ray structure affords a WBI of 0.55 , suggesting a large extent of 3c-4e bonding in this case. Judging from the refined halogen-chalcogen distances, none of the species in the present study comes close to such a bonding situation.

\section{Conclusion}

The work presented here complements our previous work on 1,8-chalcogen naphthalene derivatives ${ }^{[16]}$ and builds on the knowledge of molecular naphthalene distortion and contributes to the understanding of weak intramolecular interactions acting between heavy atoms when constrained at the close 1,8-positions. ${ }^{[1]}$ The insertion of increasingly large atoms at the peri-positions of compounds 1-8 enhances the repulsive steric strain operating in the naphthalene skeleton. Relief via molecular distortion transpires and is generally observed to a greater extent as the overall combined peri-atom size increases (Figures 4 and 5) however, the number, size and nature of substituents bound to the peri-atoms can also affect the conformation of the molecule. The degree of deviation from an 'ideal' geometry ${ }^{[3]}$ can be quantified by the peridistance which encapsulates all molecular distortions in one entity. 
The largest peri-distances were found in $\mathbf{4}$ and $\mathbf{8}$; the large tellurium and iodine atoms in $\mathbf{8}\left[\Sigma \mathrm{r}_{\mathrm{vdW}} 4.04 \AA{ }^{[24]}\right.$ experience a greater degree of steric congestion, whilst the axial conformation of the naphthyl ring relative to the $\mathrm{C}(\mathrm{ar})$ - $\mathrm{E}-\mathrm{C}(\mathrm{ar})$ plane in 4 results in greater repulsion between lone-pairs. ${ }^{[27]}$ The shortest peri-gap is observed in $\mathbf{1}$ containing the two smallest (sulfur and bromine) substituents $\left[\Sigma \mathrm{r}_{\mathrm{vdW}} 3.65 \AA\right] .{ }^{[24]}$ In all derivatives the non-bonded distance was shorter than the sum of van der Waals radii for the two peri-atoms by $12-18 \%$.

The contrasting conformation of $\mathbf{4}$ is the most notable difference observed in the series of compounds. Whilst 5-8 all adopt the type $\mathrm{B}$ structure with $\mathrm{E}-\mathrm{C}_{\mathrm{Ph}}$ bonds aligning close to the naphthyl plane ${ }^{[2,8,9,11]}$ and a mixed equatorial-axial arrangement of naphthyl and phenyl rings around the chalcogen atom, ${ }^{[27]} 4$ arranges with the $\mathrm{S}-\mathrm{C}_{\mathrm{Ph}}$ bond perpendicular to the plane and adopts an axial-equatorial conformation for the naphthyl and phenyl rings. ${ }^{[2,8,9,11,27]}$ This indicates that chalcogen p-type lone pair repulsion is more dominant in $\mathbf{4}$ compared with $\mathbf{5 - 8}$ [27] $^{[2]}$

The orientation of the E(phenyl) moiety in 5-8 allows for a possible attractive 3c-4e interaction due to a quasi-linear arrangement of the type $\mathrm{X} \cdots \mathrm{E}-\mathrm{C}_{\mathrm{Ph}}$. In each of the four derivatives angles approach $180^{\circ}\left[173.1-175.7^{\circ}\right]$ and non-bonded $\mathrm{X} \cdots \mathrm{E}$ distances are all shorter than the sum of respective van der Waals radii. Ab initio MO calculations performed on all four derivatives, using B3LYP/6-31+G* level, revealed Wiberg bond index (WBI ${ }^{[32]}$ values of $0.05-0.08$, indicating only a very minor interaction exists between the non-bonded atoms and refined halogen-chalcogen distances don't come close to those of a $3 \mathrm{c}-4 \mathrm{e}$ interaction.

\section{Experimental Section}

All experiments were carried out under an oxygen- and moisture-free nitrogen atmosphere using standard Schlenk techniques and glassware. Reagents were obtained from commercial sources and used as received. Dry solvents were collected from a MBraun solvent system. 1,8-dibromonaphthalene $\mathbf{1 1}^{[22]}$ and 1,8-diiodonaphthalene $\mathbf{1 2}^{[23]}$ were prepared via standard diazotisation reactions of 1,8-diaminonaphthalene. Elemental analyses were performed by the University of St. Andrews School of Chemistry Microanalysis Service. Infra-red spectra were recorded as KBr discs in the range 4000-300 $\mathrm{cm}^{-1}$ on a Perkin-Elmer System 2000 Fourier transform spectrometer. ${ }^{1} \mathrm{H}$ and ${ }^{13} \mathrm{C}$ NMR spectra were recorded on a Jeol GSX $270 \mathrm{MHz}$ spectrometer with $\delta(\mathrm{H})$ and $\delta(\mathrm{C})$ referenced to external tetramethylsilane. ${ }^{77}$ Se and ${ }^{125}$ Te NMR spectra were recorded on a Jeol GSX $270 \mathrm{MHz}$ spectrometer with $\delta(\mathrm{Se})$ and $\delta(\mathrm{Te})$ referenced to external dimethylselenide and diphenyl ditelluride respectively. Assignments of ${ }^{13} \mathrm{C}$ and ${ }^{1} \mathrm{H}$ NMR spectra were made with the help of H-H COSY and HSQC experiments. All measurements were performed at $25^{\circ} \mathrm{C}$. All values reported for NMR spectroscopy are in parts per million (ppm). Coupling constants $(J)$ are given in Hertz (Hz). Mass spectrometry was performed by the University of St. Andrews Mass Spectrometry Service. Electron impact mass spectrometry (EIMS) and Chemical Ionisation Mass Spectrometry (CIMS) was carried out on a Micromass GCT orthogonal acceleration time of flight mass spectrometer. Electrospray Mass Spectrometry (ESMS) was carried out on a Micromass LCT orthogonal accelerator time of flight mass spectrometer.

1-Bromo-8-(ethylsulfanyl)naphthalene Nap[Br][SEt] (1) from (9): To a solution of 1,8-dibromonaphthalene (0.6 g, $2.2 \mathrm{mmol})$ in diethyl ether $(10 \mathrm{~mL})$ at $-78^{\circ} \mathrm{C}$ was added dropwise a $2.5 \mathrm{M}$ solution of $n$-butyllithium in hexane $(0.9 \mathrm{~mL}$, $2.2 \mathrm{mmol})$. The mixture was stirred at this temperature for $1 \mathrm{~h}$ after which a solution of diethyl disulfide $(0.3 \mathrm{~g}, 0.3 \mathrm{~mL}$, 
$2.2 \mathrm{mmol}$,) was added dropwise to the mixture. The resulting mixture was stirred at $-78{ }^{\circ} \mathrm{C}$ for a further $1 \mathrm{~h}$. The reaction mixture was washed with $0.1 \mathrm{M}$ sodium hydroxide $(20 \mathrm{~mL}$ x 2). The organic layer was dried with magnesium sulfate, concentrated under reduced pressure, and the residual yellow oil was purified by column chromatography on silica gel (hexane) to give the product as a brown solid. Recrystallisation from dichloromethane/pentane gave colourless crystals $(0.3 \mathrm{~g}, 43 \%)$; m.p./b.p. $47-49^{\circ} \mathrm{C}$ (lit., $\left.{ }^{[7]} 47-48^{\circ} \mathrm{C}\right) ;{ }^{1} \mathrm{H}$ NMR $\left(270 \mathrm{MHz}, \mathrm{CDCl}_{3}, 25^{\circ} \mathrm{C}\right.$, TMS) $\delta=7.75\left(\mathrm{dd},{ }^{3} J\right.$ $(\mathrm{H}, \mathrm{H})=7.4 \mathrm{~Hz},{ }^{4} J(\mathrm{H}, \mathrm{H})=1.2 \mathrm{~Hz}, 1 \mathrm{H}$; nap 4-H), $7.68\left(\mathrm{dd},{ }^{3} J(\mathrm{H}, \mathrm{H})=8.1 \mathrm{~Hz},{ }^{4} J(\mathrm{H}, \mathrm{H})=1.1 \mathrm{~Hz}, 1 \mathrm{H}\right.$; nap 2-H), 7.55 $\left(\mathrm{dd},{ }^{3} J(\mathrm{H}, \mathrm{H})=8.0 \mathrm{~Hz},{ }^{4} J(\mathrm{H}, \mathrm{H})=1.1 \mathrm{~Hz}, 1 \mathrm{H}\right.$; nap $\left.5-\mathrm{H}\right), 7.42\left(\mathrm{dd},{ }^{3} J(\mathrm{H}, \mathrm{H})=7.5 \mathrm{~Hz},{ }^{4} J(\mathrm{H}, \mathrm{H})=1.0 \mathrm{~Hz}, 1 \mathrm{H} ;\right.$ nap $\left.7-\mathrm{H}\right)$, $7.28\left(\mathrm{t},{ }^{3} \mathrm{~J}(\mathrm{H}, \mathrm{H})=7.8 \mathrm{~Hz}, 1 \mathrm{H}\right.$; nap 6-H), $7.14\left(\mathrm{t},{ }^{3} \mathrm{~J}(\mathrm{H}, \mathrm{H})=7.8 \mathrm{~Hz}, 1 \mathrm{H}\right.$; nap 3-H), $2.92\left(\mathrm{q},{ }^{3} \mathrm{~J}(\mathrm{H}, \mathrm{H})=7.3 \mathrm{~Hz}, 2 \mathrm{H}\right.$; $\left.\mathrm{CH}_{2}\right), 1.28\left(\mathrm{t},{ }^{3} \mathrm{~J}(\mathrm{H}, \mathrm{H})=7.4 \mathrm{~Hz}, 3 \mathrm{H} ; \mathrm{CH}_{3}\right) ;{ }^{13} \mathrm{C} \mathrm{NMR}\left(67.9 \mathrm{MHz}, \mathrm{CDCl}_{3}, 25{ }^{\circ} \mathrm{C}, \mathrm{TMS}\right): \delta=136.9(\mathrm{q}), 136.1(\mathrm{q})$, 134.2(s), 130.8(q), 129.5(s), 127.8(s), 127.1(s), 126.2(s), 125.9(s), 119.4(q), 30.0(s; $\left.\mathrm{CH}_{2}\right), 13.4\left(\mathrm{~s} ; \mathrm{CH}_{3}\right) ; \mathrm{IR}(\mathrm{KBr} \operatorname{disk})$ : $v_{\max } \mathrm{cm}^{-1}:$ 3056w, 2971w, 2925w, 2851w, 1923w, 1544vs, 1511w, 1493w, 1461w, 1434w, 1416w, 1356s, 1308s, 1256w, 1191vs, 1148s, 1057w, 967s, 857s, 801vs, 702s, 545w, 439w; MS $\left(\mathrm{CI}^{+}\right): m / z(\%): 266.0(100)\left[\mathrm{M}^{+}+\mathrm{H}\right]$; elemental analysis calcd (\%) for $\mathrm{C}_{12} \mathrm{H}_{11} \mathrm{BrS}$ : C 54.0, H 4.2; found: C 54.1, H 4.3.

1-Iodo-8-(ethylsulfanyl)naphthalene Nap[I][SEt] (2) from (10): To a solution of 1,8-diiodonaphthalene (0.88 g, 2.3 $\mathrm{mmol})$ in diethyl ether $(10 \mathrm{~mL})$ at $-78^{\circ} \mathrm{C}$ was added dropwise a $2.5 \mathrm{M}$ solution of $n$-butyllithium in hexane $(0.9 \mathrm{~mL}, 2.3$ $\mathrm{mmol})$. The mixture was stirred at this temperature for $1 \mathrm{~h}$ after which a solution of diethyl disulfide $(0.28 \mathrm{~g}, 0.3 \mathrm{~mL}$, $2.3 \mathrm{mmol}$ ) was added dropwise. The resulting solution was stirred at $-78^{\circ} \mathrm{C}$ for a further $1 \mathrm{~h}$ and then was washed with $0.1 \mathrm{M}$ sodium hydroxide (20 mL x 2). The organic layer was dried with magnesium sulfate, concentrated under reduced pressure, and the residual brown oil was purified by column chromatography on silica gel (hexane) to give the product as a yellow sold. Recrystallisation from dichloromethane/pentane gave colourless crystals (0.3 g, 42 \%); m.p./b.p. 53 $55^{\circ} \mathrm{C} ;{ }^{1} \mathrm{H}$ NMR $\left(270 \mathrm{MHz}, \mathrm{CDCl}_{3}, 25^{\circ} \mathrm{C}, \mathrm{TMS}\right) \delta=8.26\left(\mathrm{dd},{ }^{3} J(\mathrm{H}, \mathrm{H})=7.4 \mathrm{~Hz},{ }^{4} J(\mathrm{H}, \mathrm{H})=1.3 \mathrm{~Hz}, 1 \mathrm{H}\right.$; nap 4-H), 7.74 $\left(\mathrm{dd},{ }^{3} J(\mathrm{H}, \mathrm{H})=8.1 \mathrm{~Hz},{ }^{4} J(\mathrm{H}, \mathrm{H})=1.2 \mathrm{~Hz}, 1 \mathrm{H}\right.$; nap 2-H), 7.67-7.58 (m, $2 \mathrm{H}$; nap 5,7-H), 7.31 (t, ${ }^{3} J(\mathrm{H}, \mathrm{H})=7.7 \mathrm{~Hz}, 1 \mathrm{H}$; nap 6-H), 7.02-6.95 (m, $1 \mathrm{H}$; nap 3-H), $2.89\left(\mathrm{q},{ }^{3} J(\mathrm{H}, \mathrm{H})=7.4 \mathrm{~Hz}, 2 \mathrm{H} ; \mathrm{SCH}_{2}\right), 1.22\left(\mathrm{t},{ }^{3} J(\mathrm{H}, \mathrm{H})=7.4 \mathrm{~Hz}, 3 \mathrm{H}\right.$; $\left.\mathrm{SCH}_{2} \mathrm{CH}_{3}\right) ;{ }^{13} \mathrm{C}$ NMR $\left(67.9 \mathrm{MHz}, \mathrm{CDCl}_{3}, 25{ }^{\circ} \mathrm{C}, \mathrm{TMS}\right): \delta=143.3(\mathrm{~s}), 131.3(\mathrm{~s}), 130.4(\mathrm{~s}), 128.7(\mathrm{~s}), 126.8(\mathrm{~s}), 125.6(\mathrm{~s})$ 31.9(s; $\left.\mathrm{CH}_{2}\right), 13.6\left(\mathrm{~s} ; \mathrm{CH}_{3}\right)$; IR (KBr disk): $v_{\max } \mathrm{cm}^{-1}: 3412 \mathrm{br}, 3051 \mathrm{w}, 2965 \mathrm{w}, 2924 \mathrm{~s}, 1539 \mathrm{~s}, 1500 \mathrm{w}, 1440 \mathrm{w}, 1372 \mathrm{w}$, 1354w, 1308w, 1259s, 1190s, 1142w, 1096w, 1049w, 1020w, 963w, 942w, 898w, 849w, 790vs, 762vs, 689w, 642w, 561w, 538w, 401w; MS $\left(\mathrm{EI}^{+}\right): \mathrm{m} / z(\%): 314.0(22)\left[\mathrm{M}^{+}\right], 254.0(72)\left[\mathrm{M}^{+}-\mathrm{SEt}\right]$; elemental analysis calcd (\%) for $\mathrm{C}_{10} \mathrm{H}_{6} \mathrm{I}_{2}: \mathrm{C} 45.9, \mathrm{H} 3.5$; found: C 46.7, H 3.1.

1-Bromo-8-(phenylsulfanyl)naphthalene Nap[Br][SPh] (3) from (9): To a solution of 1,8-dibromonaphthalene (0.67 $\mathrm{g}, 2.3 \mathrm{mmol})$ in diethyl ether $(15 \mathrm{~mL})$ at $-78^{\circ} \mathrm{C}$ was added dropwise a $2.5 \mathrm{M}$ solution of $n$-butyllithium in hexane $(0.9$ $\mathrm{mL}, 2.3 \mathrm{mmol})$. The mixture was stirred at this temperature for $1 \mathrm{~h}$ after which a solution of diphenyl disulfide $(0.51 \mathrm{~g}$, $2.3 \mathrm{mmol})$ in diethyl ether $(15 \mathrm{~mL})$ was added dropwise to the mixture. The resulting mixture was stirred at $-78^{\circ} \mathrm{C}$ for a further $1 \mathrm{~h}$. The reaction mixture was washed with $0.1 \mathrm{M}$ sodium hydroxide $(2 \times 45 \mathrm{~mL})$. The organic layer was dried with magnesium sulfate, concentrated under reduced pressure, and the residual brown oil was purified by column chromatography on silica gel (hexane/ethyl acetate 20:1) to give the product as a brown oil $(0.7 \mathrm{~g}, 51 \%) ;{ }^{1} \mathrm{H}$ NMR $(270$ $\left.\mathrm{MHz}, \mathrm{CDCl}_{3}, 25^{\circ} \mathrm{C}, \mathrm{TMS}\right) \delta=7.80\left(\mathrm{dd},{ }^{3} J(\mathrm{H}, \mathrm{H})=7.4 \mathrm{~Hz},{ }^{4} J(\mathrm{H}, \mathrm{H})=1.3 \mathrm{~Hz}, 1 \mathrm{H} ;\right.$ nap 4-H), $7.73\left(\mathrm{dd},{ }^{3} J(\mathrm{H}, \mathrm{H})=8.2\right.$ $\mathrm{Hz},{ }^{4} J(\mathrm{H}, \mathrm{H})=1.1 \mathrm{~Hz}, 1 \mathrm{H}$; nap 2-H), $7.65\left(\mathrm{dd},{ }^{3} J(\mathrm{H}, \mathrm{H})=8.1 \mathrm{~Hz},{ }^{4} J(\mathrm{H}, \mathrm{H})=1.2 \mathrm{~Hz}, 1 \mathrm{H}\right.$; nap 5-H), $7.55\left(\mathrm{dd},{ }^{3} J(\mathrm{H}, \mathrm{H})\right.$ $=7.5 \mathrm{~Hz},{ }^{4} \mathrm{~J}(\mathrm{H}, \mathrm{H})=1.3 \mathrm{~Hz}, 1 \mathrm{H}$; nap 7-H), 7.28-7.14 (m, $7 \mathrm{H}$; nap 3,6-H, SPh 2-6-H); ${ }^{13} \mathrm{C}$ NMR $\left(67.9 \mathrm{MHz}, \mathrm{CDCl}_{3}, 25\right.$ $\left.{ }^{\circ} \mathrm{C}, \mathrm{TMS}\right): \delta=137.6(\mathrm{~s}), 133.2(\mathrm{~s}), 131.9(\mathrm{~s}), 129.53(\mathrm{~s}), 129.49(\mathrm{~s}), 128.9(\mathrm{~s}), 127.4(\mathrm{~s}), 126.4(\mathrm{~s}), 126.1(\mathrm{~s})$. 
1-Iodo-8-(phenylsulfanyl)naphthalene Nap[I][SPh] (4) from (10): To a solution of 1,8-diiodonaphthalene (0.47 g, $1.2 \mathrm{mmol})$ in diethyl ether $(15 \mathrm{~mL})$ at $-78^{\circ} \mathrm{C}$ was added dropwise a $2.5 \mathrm{M}$ solution of $n$-butyllithium in hexane $(0.5 \mathrm{~mL}$, $1.2 \mathrm{mmol})$. The mixture was stirred at this temperature for $1 \mathrm{~h}$ after which a solution of diphenyl disulfide $(0.27 \mathrm{~g}, 1.2$ mmol) in diethyl ether $(15 \mathrm{~mL})$ was added dropwise to the mixture. The resulting mixture was stirred at $-78{ }^{\circ} \mathrm{C}$ for a further $1 \mathrm{~h}$. The reaction mixture was washed with $0.1 \mathrm{M}$ sodium hydroxide $(2 \mathrm{x} 45 \mathrm{~mL})$. The organic layer was dried with magnesium sulfate, concentrated under reduced pressure and the residual yellow oil was purified by column chromatography on silica gel (hexane) and the resulting yellow solid was recrystallised from dichloromethane/pentane to give colourless crystals $\left(0.1 \mathrm{~g}, 26 \%\right.$ ); m.p./b.p. $47-49^{\circ} \mathrm{C} ;{ }^{1} \mathrm{H}$ NMR $\left(270 \mathrm{MHz}, \mathrm{CDCl}_{3}, 25^{\circ} \mathrm{C}, \mathrm{TMS}\right) \delta=8.27$ (dd, ${ }^{3} J$ $(\mathrm{H}, \mathrm{H})=7.4 \mathrm{~Hz},{ }^{4} J(\mathrm{H}, \mathrm{H})=1.3 \mathrm{~Hz}, 1 \mathrm{H}$; nap 4-H), $7.79\left(\mathrm{dd},{ }^{3} J(\mathrm{H}, \mathrm{H})=8.1 \mathrm{~Hz},{ }^{4} J(\mathrm{H}, \mathrm{H})=1.2 \mathrm{~Hz}, 1 \mathrm{H}\right.$; nap 2-H), 7.75 $\left(\mathrm{dd},{ }^{3} J(\mathrm{H}, \mathrm{H})=8.2 \mathrm{~Hz},{ }^{4} J(\mathrm{H}, \mathrm{H})=1.3 \mathrm{~Hz}, 1 \mathrm{H}\right.$; nap 5-H), $7.64\left(\mathrm{dd},{ }^{3} J(\mathrm{H}, \mathrm{H})=7.3 \mathrm{~Hz},{ }^{4} J(\mathrm{H}, \mathrm{H})=1.4 \mathrm{~Hz}, 1 \mathrm{H}\right.$; nap 7-H), 7.33-7.26 (m, $1 \mathrm{H}$, nap 6-H), 7.21-6.97 (m, $6 \mathrm{H}$, nap 3-H, SPh 2-6-H); ${ }^{13} \mathrm{C}$ NMR $\left(67.9 \mathrm{MHz}, \mathrm{CDCl}_{3}, 25^{\circ} \mathrm{C}, \mathrm{TMS}\right): \delta=$ 143.9(s), 136.4(s), 130.7(s), 130.5(s), 129.7(s), 129.3(s), 127.1(s), 126.3(s), 126.0(s); IR (KBr disk): $v_{\max } \mathrm{cm}^{-1}: 3442 \mathrm{br}$, 3056w, 2955s, 2924s, 2848w, 1937w, 1790w, 1719w, 1654w, 1578s, 1535s, 1474s, 1432s, 1346w, 1314w, 1261s, 1187s, 1080vs, 1022vs, 959w, 891w, 850w, 815vs, 755vs, 733vs, 688s, 613w, 566w, 516w, 462w, 400w; MS (ES ${ }^{+}$): $m / z(\%): 384.80(100)\left[\mathrm{M}^{+}+\mathrm{Na}\right]$; elemental analysis calcd (\%) for $\mathrm{C}_{16} \mathrm{H}_{11} \mathrm{IS}$ : C 53.0, H 3.1; found: C 53.0, $\mathrm{H}$ 3.4.

1-Bromo-8-(phenylselanyl)naphthalene Nap[Br][SePh] (5) from (9): To a solution of 1,8-dibromonaphthalene (5.0 $\mathrm{g}, 0.018 \mathrm{~mol})$ in diethyl ether $(35 \mathrm{~mL})$ at $-78{ }^{\circ} \mathrm{C}$ was added dropwise a $2.5 \mathrm{M}$ solution of $n$-butyllithium in hexane $(7$ $\mathrm{mL}, 0.018 \mathrm{~mol})$. The mixture was stirred at this temperature for $1 \mathrm{~h}$ after which a solution of diphenyl diselenide $(5.45$ $\mathrm{g}, 0.018 \mathrm{~mol})$ in diethyl ether $(10 \mathrm{~mL})$ was added dropwise to the mixture. The resulting mixture was stirred at $-78^{\circ} \mathrm{C}$ for a further $1 \mathrm{~h}$. The reaction mixture was washed with $0.1 \mathrm{M}$ sodium hydroxide $(2 \mathrm{x} 45 \mathrm{~mL})$. The organic layer was dried with magnesium sulfate and concentrated under reduced pressure. The residual brown oil was purified by column chromatography on silica gel (hexane/dichloromethane 20:1) and the resulting green/brown solid was recrystallised from dichloromethane/pentane to give colourless crystals $\left(4.0 \mathrm{~g}, 63 \%\right.$ ); m.p./b.p. $77-79^{\circ} \mathrm{C}$ (lit., $\left.{ }^{[8]} 78^{\circ} \mathrm{C}\right) ;{ }^{1} \mathrm{H} \mathrm{NMR}(270$ $\left.\mathrm{MHz}_{\mathrm{CDCl}}, 25^{\circ} \mathrm{C}, \mathrm{TMS}\right) \delta=7.88\left(\mathrm{dd},{ }^{3} J(\mathrm{H}, \mathrm{H})=7.4 \mathrm{~Hz},{ }^{4} J(\mathrm{H}, \mathrm{H})=1.2 \mathrm{~Hz}, 1 \mathrm{H}\right.$; nap 4-H), $7.81\left(\mathrm{~d},{ }^{3} J(\mathrm{H}, \mathrm{H})=8.1\right.$ Hz, 1 H; nap 2-H), 7.74-7.59 (m, 3 H; nap 5-H, SPh 2,6-H), 7.49-7.36 (m, 3 H; SPh 3-5-H), 7.34-7.22 (m, 2 H; nap 3,7$\mathrm{H}), 7.19-7.09$ (m, $1 \mathrm{H}$; nap 6-H); ${ }^{13} \mathrm{C}$ NMR (67.9 MHz, $\left.\mathrm{CDCl}_{3}, 25{ }^{\circ} \mathrm{C}, \mathrm{TMS}\right): \delta=137.1(\mathrm{q}), 136.8(\mathrm{~s}), 133.5(\mathrm{q}), 133.4(\mathrm{~s})$, 132.1(q), 131.7(q), 130.9(s), 130.0(s), 129.4(s), 128.9(s), 127.6(s), 126.4(s), 126.2(s), 120.6(q); ${ }^{77} \mathrm{Se} \mathrm{NMR} \mathrm{(51.5} \mathrm{MHz,}$ $\left.\mathrm{CDCl}_{3}, 25^{\circ} \mathrm{C}, \mathrm{PhSeSePh}\right): \delta=447.8$; IR (KBr disk): $v_{\max } \mathrm{cm}^{-1}: 3058 \mathrm{w}, 2955 \mathrm{w}, 2925 \mathrm{w}, 1787 \mathrm{w}, 1573 \mathrm{w}, 1541 \mathrm{~s}, 1473 \mathrm{w}$, 1462w, 1434s, 1353w, 1299w, 1269w, 1187s, 1139s, 1089w, 1061w, 1020w, 997w, 953w, 903w, 841w, 806vs, 746vs, 691vs, 557w, 533w, 476w, 436w, 315w; MS $\left(\mathrm{EI}^{+}\right): \mathrm{m} / \mathrm{z}(\%): 361.9(100)\left[\mathrm{M}^{+}\right]$; elemental analysis calcd $(\%)$ for $\mathrm{C}_{16} \mathrm{H}_{11}$ BrSe: C 53.0, H 3.1; found: C 52.6, H 3.6.

1-Iodo-8-(phenylselanyl)naphthalene $\mathbf{N a p}[\mathbf{I}][\mathrm{SePh}]$ (6) from (10): To a solution of 1,8-diiodonaphthalene $(0.49 \mathrm{~g}$, $1.3 \mathrm{mmol})$ in diethyl ether $(15 \mathrm{~mL})$ at $-78{ }^{\circ} \mathrm{C}$ was added dropwise a $2.5 \mathrm{M}$ solution of $n$-butyllithium in hexane $(0.5 \mathrm{~mL}$, $1.3 \mathrm{mmol})$. The mixture was stirred at this temperature for $1 \mathrm{~h}$ after which a solution of diphenyl diselenide $(0.40 \mathrm{~g}, 1.3$ mmol) in diethyl ether $(15 \mathrm{~mL})$ was added dropwise to the mixture. The resulting mixture was stirred at $-78{ }^{\circ} \mathrm{C}$ for a further $1 \mathrm{~h}$. The reaction mixture was washed with $0.1 \mathrm{M}$ sodium hydroxide $(2 \mathrm{x} 45 \mathrm{~mL})$. The organic layer was dried with magnesium sulfate and concentrated under reduced pressure. The crude brown solid was purified by column chromatography on silica gel (hexane) and recrystallised from dichloromethane/pentane to give colourless crystals (0.3 
g, $60 \%)$; m.p./b.p. $56-58^{\circ} \mathrm{C} ;{ }^{1} \mathrm{H}$ NMR $\left(270 \mathrm{MHz}, \mathrm{CDCl}_{3}, 25^{\circ} \mathrm{C}, \mathrm{TMS}\right) \delta=8.22\left(\mathrm{dd},{ }^{3} J(\mathrm{H}, \mathrm{H})=7.4 \mathrm{~Hz},{ }^{4} J(\mathrm{H}, \mathrm{H})=1.3\right.$ $\mathrm{Hz}, 1 \mathrm{H}$; nap 4-H), $7.74\left(\mathrm{dd},{ }^{3} J(\mathrm{H}, \mathrm{H})=8.1 \mathrm{~Hz},{ }^{4} J(\mathrm{H}, \mathrm{H})=1.0 \mathrm{~Hz}, 1 \mathrm{H}\right.$; nap 2-H), $7.57\left(\mathrm{dd},{ }^{3} J(\mathrm{H}, \mathrm{H})=8.0 \mathrm{~Hz},{ }^{4} J(\mathrm{H}, \mathrm{H})\right.$ $=1.1 \mathrm{~Hz}, 1 \mathrm{H}$; nap 5-H), 7.49-7.43 (m, $2 \mathrm{H} ; \mathrm{SPh} 2,6-\mathrm{H}), 7.35\left(\mathrm{dd},{ }^{3} J(\mathrm{H}, \mathrm{H})=7.5 \mathrm{~Hz},{ }^{4} J(\mathrm{H}, \mathrm{H})=1.2 \mathrm{~Hz}, 1 \mathrm{H} ;\right.$ nap 7-H), 7.32-7.24 (m, $3 \mathrm{H}$; SPh 3-5-H), 7.12-6.99 (m, $2 \mathrm{H}$; nap 3,6-H); ${ }^{13} \mathrm{C}$ NMR (67.9 MHz, $\mathrm{CDCl}_{3}, 25{ }^{\circ} \mathrm{C}$, TMS): $\delta=$ 142.2(s), 135.6(s), 133.1(s), 130.2(s), 129.8(s), 128.6(s), 128.4(s), 126.8(s), 126.3(s); ${ }^{77} \mathrm{Se} \mathrm{NMR}\left(51.5 \mathrm{MHz}, \mathrm{CDCl}_{3}, 25\right.$ $\left.{ }^{\circ} \mathrm{C}, \mathrm{PhSeSePh}\right): \delta=430.8$; IR (KBr disk): $v_{\max } \mathrm{cm}^{-1}: 3442 \mathrm{br}, 3051 \mathrm{~s}, 1961 \mathrm{w}, 1911 \mathrm{w}, 1887 \mathrm{w}, 1778 \mathrm{w}, 1633 \mathrm{w}, 1571 \mathrm{~s}$, 1537vs, 1488w, 1473s, 1434s, 1349s, 1311s, 1299s, 1272w, 1185s, 1133s, 1089w, 1062s, 1018s, 997w, 947w, 897w, 829w, 804vs, 742vs, 691vs, 607w, 551w, 524w, 474s, 427w, 306w; MS (EI+): $\mathrm{m} / z(\%): 409.9(51)\left[\mathrm{M}^{+}\right]$; elemental analysis calcd (\%) for $\mathrm{C}_{16} \mathrm{H}_{11} \mathrm{ISe}$ : C 47.0, $\mathrm{H}$ 2.7; found: $\mathrm{C} 47.0, \mathrm{H} 2.5$.

1-Bromo-8-(phenyltelluro)naphthalene $\mathrm{Nap}[\mathrm{Br}][\mathrm{TePh}]$ (7) from (9): To a solution of 1,8-dibromonaphthalene (0.55 $\mathrm{g}, 1.9 \mathrm{~mol})$ in diethyl ether $(35 \mathrm{~mL})$ at $-78^{\circ} \mathrm{C}$ was added dropwise a $2.5 \mathrm{M}$ solution of $n$-butyllithium in hexane $(0.5 \mathrm{~mL}$, $1.9 \mathrm{~mol})$. The mixture was stirred at this temperature for $1 \mathrm{~h}$ after which a solution of diphenyl ditelurride $(0.79 \mathrm{~g}, 1.9$ mol) in diethyl ether $(20 \mathrm{~mL})$ was added dropwise to the mixture. The resulting mixture was stirred at $-78{ }^{\circ} \mathrm{C}$ for a further $1 \mathrm{~h}$. The reaction mixture was washed with $0.1 \mathrm{M}$ sodium hydroxide $(2 \times 45 \mathrm{~mL})$. The organic layer was dried with magnesium sulfate, concentrated under reduced pressure and the resulting golden solid was purified by column chromatography on silica gel (ethyl acetate/hexane 1:20). Recrystallisation from dichloromethane/pentane afforded colourless crystals $(0.3 \mathrm{~g}, 32 \%)$; m.p./b.p. $105-107^{\circ} \mathrm{C} ;{ }^{1} \mathrm{H}$ NMR $\left(270 \mathrm{MHz}, \mathrm{CDCl}_{3}, 25^{\circ} \mathrm{C}\right.$, TMS) $\delta=8.02-7.92$ (m, 2 $\mathrm{H}$; TePh 2,6-H), $7.80\left(\mathrm{dd},{ }^{3} J(\mathrm{H}, \mathrm{H})=7.5 \mathrm{~Hz},{ }^{4} J(\mathrm{H}, \mathrm{H})=1.3 \mathrm{~Hz}, 1 \mathrm{H} ;\right.$ nap 5-H), $7.76\left(\mathrm{dd},{ }^{3} J(\mathrm{H}, \mathrm{H})=8.3 \mathrm{~Hz},{ }^{4} J(\mathrm{H}, \mathrm{H})=\right.$ $1.1 \mathrm{~Hz}, 1 \mathrm{H}$; nap 7-H), 7.63-7.55 (m, $1 \mathrm{H}$; nap 4-H), 7.52-7.41 (m, $2 \mathrm{H}$; nap 2-H, TePh 4-H), 7.41-7.31 (m, 2 H; TePh 3,5-H), 7.28-7.20 (m, $1 \mathrm{H}$; nap 6-H), $7.02\left(\mathrm{t},{ }^{3} \mathrm{~J}(\mathrm{H}, \mathrm{H})=7.7 \mathrm{~Hz}, 1 \mathrm{H}\right.$; nap 3-H); ${ }^{13} \mathrm{C}$ NMR $\left(67.9 \mathrm{MHz}, \mathrm{CDCl}_{3}, 25{ }^{\circ} \mathrm{C}\right.$, TMS): $\delta=141.3(\mathrm{~s}), 137.3(\mathrm{q}), 135.4(\mathrm{~s}), 134.0(\mathrm{q}), 132.5(\mathrm{~s}), 130.2(\mathrm{~s}), 129.8(\mathrm{~s}), 129.2(\mathrm{~s}), 128.2(\mathrm{~s}), 126.9(\mathrm{~s}), 126.1(\mathrm{~s})$, 122.5(q), 121.2(q), 117.6(q); ${ }^{125} \mathrm{Te}$ NMR (81.2 MHz, $\left.\mathrm{CDCl}_{3}, 25^{\circ} \mathrm{C}, \mathrm{PhTeTePh}\right): \delta=731.2$; IR (KBr disk): $v_{\max } \mathrm{cm}^{-1}$ : 3409w, 3056w, 2921w, 2584w, 2365w, 2343w, 1723w, 1659w, 1640w, 1568w, 1535s, 1469s, 1431s, 1385w, 1350s, 1329w, 1299w, 1262w, 1185s, 1133s, 1059s, 1015s, 996s, 946w, 908w, 834s, 804vs, 739vs, 692s, 602w, 553w, 527w, 459s; MS (CI+): $m / z(\%): 411.9(85)\left[\mathrm{M}^{+}\right], 334.9(45)\left[\mathrm{M}^{+}-\mathrm{Ph}\right]$; elemental analysis calcd (\%) for $\mathrm{C}_{16} \mathrm{H}_{11} \mathrm{BrTe}$ : $\mathrm{C} 46.8, \mathrm{H}$ 2.7; found: C 46.8, $\mathrm{H} 2.7$.

1-Iodo-8-(phenyltelluro)naphthalene Nap[I][TePh] (8) from (10): To a solution of 1,8-diiodonaphthalene (0.43 g, $1.1 \mathrm{~mol})$ in diethyl ether $(35 \mathrm{~mL})$ at $-78^{\circ} \mathrm{C}$ was added dropwise a $2.5 \mathrm{M}$ solution of $n$-butyllithium in hexane $(0.5 \mathrm{~mL}$, $1.1 \mathrm{~mol})$. The mixture was stirred at this temperature for $1 \mathrm{~h}$ after which a solution of diphenyl ditelluride $(0.46 \mathrm{~g}, 1.1$ mol) in diethyl ether $(20 \mathrm{~mL})$ was added dropwise to the mixture. The resulting mixture was stirred at $-78{ }^{\circ} \mathrm{C}$ for a further $1 \mathrm{~h}$. The reaction mixture was washed with $0.1 \mathrm{M}$ sodium hydroxide $(2 \times 45 \mathrm{~mL})$. The organic layer was dried with magnesium sulfate, concentrated under reduced pressure and the resulting golden solid was purified by column chromatography on silica gel (ethyl acetate/hexane 1:20). Recrystallisation of the golden solid from dichloromethane/pentane gave colourless crystals $\left(0.09\right.$ g, $18 \%$ ); m.p./b.p. 109-111 ${ }^{\circ} \mathrm{C} ;{ }^{1} \mathrm{H}$ NMR $\left(270 \mathrm{MHz}, \mathrm{CDCl}_{3}, 25\right.$ $\left.{ }^{\circ} \mathrm{C}, \mathrm{TMS}\right) \delta=8.11\left(\mathrm{dd},{ }^{3} J(\mathrm{H}, \mathrm{H})=7.4 \mathrm{~Hz},{ }^{4} J(\mathrm{H}, \mathrm{H})=1.2 \mathrm{~Hz}, 1 \mathrm{H} ;\right.$ nap 4-H), 7.79-7.73 (m, $2 \mathrm{H} ; \mathrm{Te} P h$ 2,6-H), $7.68(\mathrm{dd}$, ${ }^{3} J(\mathrm{H}, \mathrm{H})=8.1 \mathrm{~Hz},{ }^{4} J(\mathrm{H}, \mathrm{H})=1.0 \mathrm{~Hz}, 1 \mathrm{H}$; nap 2-H), 7.53-7.46 (m, $2 \mathrm{H}$; nap 5,7-H), 7.34-7.27 (m, $1 \mathrm{H}$; TePh 4-H), 7.25-7.18 (m, 2 H; TePh 3-5-H), 7.02-6.95 (m, $1 \mathrm{H}$; nap 3-H), 6.93 (m, $1 \mathrm{H}$; nap 6-H); ${ }^{13} \mathrm{C}$ NMR (67.9 MHz, CDCl, 25 ${ }^{\circ} \mathrm{C}$, TMS $): \delta=141.0(\mathrm{~s}), 140.5(\mathrm{~s}), 137.0(\mathrm{~s}), 130.5(\mathrm{~s}), 130.0(\mathrm{~s}), 128.8(\mathrm{~s}), 128.8(\mathrm{~s}), 126.7(\mathrm{~s}), 126.6(\mathrm{~s}) ;{ }^{125} \mathrm{Te}$ NMR $(81.2$ $\left.\mathrm{MHz}, \mathrm{CDCl}_{3}, 25^{\circ} \mathrm{C}, \mathrm{PhTeTePh}\right): \delta=698.3$; IR (KBr disk): $v_{\max } \mathrm{cm}^{-1}: 3422 \mathrm{br}, 3051 \mathrm{w}, 2923 \mathrm{~s}, 2851 \mathrm{w}, 1566 \mathrm{w}, 1529 \mathrm{~s}$, 
1467w, 1430s, 1381w, 1344w, 1296w, 1256w, 1182w, 1130s, 1056w, 1013w, 996w, 942w, 905w, 823w, 802vs, 739vs, 691s, 663w, 546w, 520w, 457s; MS $\left(\mathrm{ES}^{+}\right): \mathrm{m} / \mathrm{z}(\%): 490.78(100)\left[\mathrm{M}^{+}+\mathrm{OMe}\right]$; elemental analysis calcd $(\%)$ for $\mathrm{C}_{16} \mathrm{H}_{11} \mathrm{ITe}$ C 42.0, H 2.4; found: C 42.6, H 2.6.

\section{Crystal structure analyses}

X-ray crystal structures were determined for compounds $\mathbf{1}, 5$ and $\mathbf{6}$ at $-148(1){ }^{\circ} \mathrm{C}$ on a Rigaku SCXmini CCD area detector with graphite monochromated Mo K $\alpha$ radiation $(\lambda=0.71073 \AA)$. The data were corrected for Lorentz, polarisation and absorption. Data for compound 4 were collected at $-180(1){ }^{\circ} \mathrm{C}$ by using a Rigaku MM007 High brilliance RA generator (Mo K $\alpha$ radiation, confocal optic) and Mercury CCD system. At least a full hemisphere of data was collected using $\omega$ scans. Intensities were corrected for Lorentz, polarisation and absorption. Data for compounds $\mathbf{2}$, 7 and 8 were collected at $-148(1){ }^{\circ} \mathrm{C}$ on a Rigaku ACTOR-SM, Saturn 724 CCD area detector with graphite monochromated Mo-K $\alpha$ radiation $(\lambda=0.71073 \AA)$. The data was corrected for Lorentz, polarisation and absorption. The data for the complexes analysed was collected and processed using CrystalClear (Rigaku). ${ }^{34}$ The structure was solved by direct methods ${ }^{35}$ and expanded using Fourier techniques. ${ }^{36}$ The non-hydrogen atoms were refined anisotropically. Hydrogen atoms were refined using the riding model. All calculations were performed using the CrystalStructure ${ }^{37}$ crystallographic software package except for refinement, which was performed using SHELXL-97. ${ }^{38}$ These data can be obtained free of charge via www.ccdc.cam.ac.uk/conts/retrieving.html or from the Cambridge Crystallographic Data centre, 12 Union Road, Cambridge CB2 1EZ, UK; fax (+44) 1223-336-033; e-mail: deposit@ccdc.cam.ac.uk CCDC Nos: 1 663689, 2 761964, 4 761965, 5 660322, 6 761966, 7 761967, 8761968

\section{Computational Details}

Geometries were fully optimised in the gas phase at the B3LYP level ${ }^{39}$ using Curtis and Binning's $962+(d)$ basis ${ }^{40}$ on Se and $\mathrm{Br}$, the Stuttgart-Dresden effective core potentials along with their double zeta valence basis sets for Te and $\mathrm{I}^{41}$ (augmented with d-polarisation functions with exponents of 0.237 and 0.266 , respectively), ${ }^{42}$ and 6-31+G(d) elsewhere, followed by calculation of the harmonic frequencies to confirm the minimum character of each stationary point and evaluation of Wiberg bond indices, ${ }^{32}$ obtained in a natural bond orbital ${ }^{43}$ analysis. The optimisations were started from the experimental structures available from X-ray crystallography, for which the WBIs were calculated as well. The computations were performed using the Gaussian 03 suite of programs. ${ }^{44}$

\section{Acknowledgements}

Elemental analyses were performed by Sylvia Williamson and Mass Spectrometry was performed by Caroline Horsburgh. Calculations were performed using the EaStCHEM Research Computing Facility maintained by Dr. H. Früchtl. The work in this project was supported by the Engineering and Physical Sciences Research Council (EPSRC). Michael Bühl wishes to thank EaStCHEM for support.

\section{Supporting Information Available}

X-ray crystallographic files for $\mathbf{2 , 4}, \mathbf{6 - 8}$.

\section{References}


[1] a) H. E. Katz, J. Am. Chem. Soc. 1985, 107, 1420; b) R. W. Alder, P. S. Bowman, W. R. S. Steel, D. R. Winterman, Chem. Commun. 1968, 723; c) T. Costa, H. Schimdbaur, Chem. Ber. 1982, 115, 1374; d) A. Karacar, M. Freytag, H. Thönnessen, J Omelanczuk, P. G. Jones, R. Bartsch, R. Schmutzler, Heteroat. Chem. 2001, 12, 102; e) J. Meinwald, D. Dauplaise, F. Wudl, J. J. Hauser, J. Am. Chem. Soc. 1977, 99, 255; f) R. S. Glass, S. W. Andruski, J. L. Broeker, H. Firouzabadi, L. K. Steffen, G. S. Wilson, J. Am. Chem. Soc. 1989, 111, 4036; g) T. Fuji, T. Kimura and N. Furukawa, Tetrahedron Lett. 1995, 36, 1075; h) W. Nakanishi, S. Hayahi, S. Toyota, Chem. Comm. 1996, 371; i) G. P. Schiemenz, Z. Anorg. All. Chem. 2002, 628, 2597; j) R. J. P. Corriu, J. C. Young, Hypervalent Silicon Compounds, in The Chemistry of Organic Silicon Compounds, (Eds. S. Patai, Z. Rappoport), Wiley, New York, 1989, p. 1242.

[2] a) W. Nakanishi, S. Hayashi, Phosphorus, Sulfur Silicon Relat. Elem. 2002, 177, 1833; b) W. Nakanishi, S. Hayashi, T. Uehara, J. Phys. Chem. 1999, 103, 9906.

[3] a) C. A. Coulson, R. Daudel, J. M. Robertson, Proc. R. Soc. London, Ser. A. 1951, A207, 306; b) D. W. J. Cruickshank, Acta Crystallogr. 1957, 10, 504; c) C. P. Brock, J. D. Dunitz, Acta Crystallogr., Sect. B. 1982, B38, 2218; d) J. Oddershede, S. Larsen, J. Phys. Chem. A 2004, 108, 1057.

[4] V. Balasubramaniyan, Chem. Rev. 1966, 66, 567.

[5] a) H. Schmidbaur, H.-J. Öller, D. L. Wilkinson, B. Huber, G. Müller, Chem. Ber. 1989, 122, 31; b) H. Fujihara, N. Furukawa, J. Mol. Struct. 1989, 186, 261; c) H. Fujihara, R. Akaishi, T. Erata, N. Furukawa, J. Chem. Soc., Chem. Commun. 1989, 1789; d) J. Handal, J. G. White, R. W. Franck, Y. H. Yuh, N. L. Allinger, J. Am. Chem. Soc. 1977, 99, 3345; e) J. F. Blount, F. Cozzi, J. R. Damewood, D. L. Iroff, U. Sjöstrand, K. Mislow, J. Am. Chem. Soc. 1980, 102, 99; f) F. A. L. Anet, D. Donovan, U. Sjöstrand, F. Cozzi and K. Mislow, J. Am. Chem. Soc. 1980, 102, 1748; g) W. D. Hounshell, F. A. L. Anet, F. Cozzi, J. R. Damewood Jr., C. A, Johnson, U. Sjöstrand, K. Mislow, J. Am. Chem. Soc. 1980, 102, 5941; h) R. Schröck, K. Angermaier, A. Sladek, H. Schmidbaur, Organometallics 1994, 13, 3399.

[6] P. Kilian, A. M. Z. Slawin, J. D. Woollins, Dalton Trans. 2003, 3876.

[7] G. P. Schiemenz, Z. Anorg. Allg. Chem. 2002, 628, 2597.

[8] a) W. Nakanishi, S. Hayashi, J. Org. Chem. 2002, 67, 38 and references therein; b) S. Hayashi, K. Yamane, W. Nakanishi, J. Org. Chem. 2007, 72, 7587.

[9] a) W. Nakanishi, S. Hayashi, S. Toyota, Chem. Commun. 1996, 371; b) W. Nakanishi, S. Hayashi, S. Toyota, J. Org. Chem. 1998, 63, 8790.

[10] W. Nakanishi, S. Hayashi, A. Sakaue, G. Ono, Y. Kawada, J. Am. Chem. Soc. 1998, 120, 3635.

[11] W. Nakanishi, S. Hayashi, T. Uehara, Eur. J. Org. Chem. 2001, 3933.

[12] a) W. Nakanishi, S. Hayashi, J. Phys. Chem. A 1999, 103, 6074; b) S. Hayashi, W. Nakanishi, J. Org. Chem. 1999, 64, 6688; c) W. Nakanishi, S. Hayashi, T. Arai, Chem. Commun. 2002, 2416; d) S. Hayashi, H. Wada, T. Ueno, W. Nakanishi, J. Org. Chem. 2006, 71, 5574; e) S. Hayashi, W. Nakanishi, Bull. Chem. Soc. Jpn. 2008, 81(12), 1605; f) S. Hayashi, W. Nakanishi, A. Furuta, J. Drabowicz, T. Sasamori, N. Tokitoh, New J. Chem. 2009, 33, 196.

[13] a) S. M. Aucott, H. L. Milton, S. D. Robertson, A. M. Z. Slawin, G. D. Walker, J. D. Woollins. Chemistry Eur. J. 2004, 10, 1666-1676: b) S. M. Aucott, H. L. Milton, S. D. Robertson, A. M. Z. Slawin, J. D. Woollins, Heteroat. Chem. 2004, 15, 531-542; c) S. M. Aucott, H. L. Milton, S. D. Robertson, A. M. Z. Slawin, J. D. Woollins, Dalton Trans. 2004, 3347-3352: d) S. M. Aucott, P. Kilian, H. L. Milton, S. D. Robertson, A. M. Z. 
Slawin, J. D. Woollins, Inorg. Chem. 2005, 44, 2710-2718; e) S. M. Aucott, P. Kilian, S. D. Robertson, A. M. Z. Slawin, J. D. Woollins, Chem. Eur. J. 2006, 12, 895-902: f) S. M. Aucott, D. Duerden, Y. Li, A. M. Z. Slawin, J. D. Woollins, Chem. Eur. J. 2006, 12, 5495-5504.

[14] a) P. Kilian, D. Philp, A. M. Z. Slawin, J. D. Woollins, Eur. J. Inorg. Chem. 2003, 249-254: b) P. Kilian, A. M. Z. Slawin, J. D. Woollins, Chem. Eur. J. 2003, 9, 215-222; c) P. Kilian, A. M. Z. Slawin, J. D. Woollins Chem. Commun. 2003, 1174-1175; d) P. Kilian, A. M. Z. Slawin, J. D. Woollins, Dalton Trans. 2003, 3876-3885; e) P. Kilian, H. L. Milton A. M. Z. Slawin, J. D. Woollins, Inorg. Chem. 2004, 43, 2252-2260; f) P. Kilian, A. M. Z. Slawin, J. D. Woollins, Inorg. Chim. Acta 2005, 358, 1719-1713; g) P. Kilian, A. M. Z. Slawin, J. D. Woollins, Dalton Trans. 2006, 2175-2183.

[15]F. R. Knight, A. L. Fuller, A. M. Z. Slawin, J. D. Woollins, Dalton Trans. 2009, 8476-8478.

[16]F. R. Knight, A. L. Fuller, A. M. Z. Slawin, J. D. Woollins, Chem. Eur. J., accepted, chem.200903523.

[17] M. Ōki, Y. Yamada, Bull. Chem. Soc. Jpn. 1988, 61, 1191.

[18] A. L. Fuller, F. R. Knight, A. M. Z. Slawin, J. D. Woollins, Acta Crystallogr., Sect. E. 2007, E63(10), o3957.

[19] A. Toshimitsu, S. Hirao, T. Saeki, M. Asahara, K. Tamao, Heteroat. Chem. 2001, 12, 392.

[20] T. Saeki, A. Toshimitsu, K. Tamao, Organometallics 2003, 22, 3299.

[21] A. L. Fuller, F. R. Knight, A. M. Z. Slawin, J. D. Woollins, Acta Crystallogr., Sect. E. 2007, E63(9), o3855.

[22] D. Seyferth, S. C. Vick, J. Org. Chem. 1977, 141, 173.

[23] H. O. House, D. G. Koepsell, W. J. Campbell, J. Org. Chem. 1972, 37(7), 1003.

[24] A. Bondi, J. Phys. Chem. 1964, 68, 441.

[25] a) N. Lozac'h, Adv. Heterocycl. Chem. 1971, 13, 161; b) R. E. Rosenfield, Jr., R. Parthasarathy, J. D. Dunitz, J. Am. Chem. Soc. 1977, 99, 4860; c) A. Kálmán, L. Párkányi, Acta Crystallogr., Sect. B 1980, B36, 2372; d) Á. Kucsman, I. Kapovits, in Organic Sulfur Chemistry: Theoretical and Experimental Advances, (Eds. I. G. Csizmadia, A. Mangini, F. Bernardi), Elsevier, Amsterdam, 1985, p. 191; e) R. S. Glass, L. Adamowicz, J. L. Broeker, J. Am. Chem. Soc. 1991, 113, 1065; f) F. T. Burling, B. M. Goldstein, Acta Crystallogr., Sect. B 1993, B49, 738; g) Y. Nagao, T. Hirata, S. Goto, S. Sano, A. Kakehi, K. Iizuka, M. Shiro, J. Am. Chem. Soc. 1998, 120, 3104; h) K. Ohkata, M. Ohsugi, K. Yamamoto, M. Ohsawa, K. Akiba, J. Am. Chem. Soc. 1996, $118,6355$.

[26] S. A. Reiter, S. D. Nogai, K. Karaghiosoff, H. Schmidbaur, J. Am. Chem. Soc. 2004, 126, 15833.

[27] P. Nagy, D. Szabó, I. Kapovits, Á. Kucsman, G. Argay, A. Kálmán, J. Mol. Struct. 2002, 606, 61.

[28]F. H. Allen, O. Kennard, D. G. Watson, L. Brammer, A. G. Orpen, R. Taylor, J. Chem. Soc. Perkin Trans. 2 1987, $12, \mathrm{~S} 1$.

[29] J. G. Ángyán, R. A. Poirier, Á. Kucsman, I. G. Csizmadia, J. Am. Chem. Soc. 1987, 109, 2237.

[30] a) W. K. Musker, T. L. Wolford, J. Am. Chem. Soc. 1976, 98, 3055; b) W. K. Musker, P. B. Roush, J. Am. Chem. Soc. 1976, 98, 6745; c) W. K. Musker, T. L. Wolford, P. B. Roush, J. Am. Chem. Soc. 1978, 100, 6416; d) W. K. Musker, J. Am. Chem. Soc. 1978, 27, 6416; e) K. D. Asmus, Acc. Chem. Res. 1979, 12, 436; f) W. K. Musker, T. L. Wolford, P. B. Roush, Acc. Chem. Res. 1980, 13, 200; g) T. G. Brown, A. S. Hirschon, W. K. Musker, J. Phys. Chem. 1981, 85, 3767.

[31] a) R. S. Mulliken, J. Am. Chem. Soc. 1950, 72, 600; b) R. S. Mulliken, J. Am. Chem. Soc. 1952, 74, 811; c) S. P. McGlynn, Chem. Soc. Rev. 1958, 1113.

[32] K. B. Wiberg, Tetrahedron 1968, 24, 1083. 
[33] 1,6-dibromo-2-phenyl-1,2-diselenaacenaphthylene (two molecules in the unit cell with Se-Se distances of $2.516 \AA$ and 2.542 A): E. Horn, T. Nakahodo, N. Fukurawa, Z. Kristallogr. -New Cryst. Struct. 2000, $215,23$.

[34] CrystalClear 1.6: Rigaku Corporation, 1999. CrystalClear Software User's Guide, Molecular Structure Corporation, (c) 2000. J. W. P. Flugrath, Acta Crystallogr., Sect. D 1999, D55, 1718.

[35] SIR97: A. Altomare, M. Burla, M. Camalli, G. Cascarano, C. Giacovazzo, A. Guagliardi, A. Moliterni, G. Polidori, R. Spagna, J. Appl. Cryst. 1999, 32, 115.

[36] DIRDIF99: P. T. Beurskens, G. Admiraal, G. Beurskens, W. P. Bosman, R. de Gelder, R. Israel, J. M. M. Smits, 1999. The DIRDIF-99 program system, Technical Report of the Crystallography Laboratory, University of Nijmegen, The Netherlands.

[37] CrystalStructure 3.8.1: Crystal Structure Analysis Package, Rigaku and Rigaku/MSC (2000-2006). 9009 New Trails Dr. The Woodlands TX 77381 USA.

[38] SHELX97: G.M. Sheldrick, Acta Crystallogr., Sect. A 2008, 64, 112.

[39] a) A. D. Becke, J. Chem. Phys. 1993, 98, 5648; b) C. Lee, W. Yang, R. G. Parr, Phys. Rev. B 1988, $37,785$.

[40] R. C. Binning, L. A. Curtiss, J. Comput. Chem. 1990, 11, 1206.

[41] a) P. Schwerdtfeger, M. Dolg, W. H. E. Schwarz, G. A. Bowmaker, P. D. W. Boyd, J. Chem. Phys. 1989, 91, 1762; b) A. Bergner, M. Dolg, W. Kuechle, H. Stoll, H. Preuss, Mol. Phys. 1993, 80, 1431; c) for I the valence basis by Kaupp et al. (including diffuse functions) was employed: M. Kaupp, P. v. R. Schleyer, H. Stoll, H. Preuss, J. Am. Chem. Soc. 1991, 113, 6012.

[42] S. Huzinaga, J. Anzelm, M. Klobukowski, E. Radzio-Andzelm, Y. Sakai, H. Tatewaki, in Gaussian Basis Sets for Molecular Calculations, Elsevier, Amsterdam, 1984.

[43] A. E. Reed, L. A. Curtiss, F. Weinhold, Chem. Rev. 1988, 88, 899.

[44] M. J. Frisch et al, Gaussian 03, Gaussian, Inc., Pittsburgh PA, 2003. 
Table 1 Selected interatomic distances $[\AA ̊]$ and angles $\left[{ }^{\circ}\right]$ for $\mathbf{1 , ~ 2 , ~ 4 - 8}$ [values in parentheses are for independent molecules]

\begin{tabular}{|c|c|c|c|c|c|c|c|}
\hline Compound & $\mathbf{1}^{[18]}$ & 2 & 4 & $5^{[21]}$ & 6 & 7 & 8 \\
\hline \multicolumn{8}{|c|}{ Substitution Pattern - Nap[X][ER] } \\
\hline & $\mathrm{Br}, \mathrm{SEt}$ & I,SEt & $\mathrm{I}, \mathrm{SPh}$ & $\mathrm{Br}, \mathrm{SePh}$ & $\mathrm{I}, \mathrm{SePh}$ & $\mathrm{Br}, \mathrm{TePh}$ & $\mathrm{I}, \mathrm{TePh}$ \\
\hline \multicolumn{8}{|c|}{ Peri-region distances } \\
\hline \multirow[t]{2}{*}{$\mathbf{X}(\mathbf{1}) \cdots \mathbf{E}(\mathbf{1})$} & $3.0561(18)$ & $3.2436(17)$ & $3.338(11)$ & $3.1136(6)$ & $3.2524(8)$ & $3.1909(10)$ & $3.3146(6)$ \\
\hline & {$[3.0505(19)]$} & & & & & & \\
\hline \multirow[t]{2}{*}{$\Sigma \mathbf{r}_{\mathrm{vdW}}-\mathbf{X} \cdots \mathbf{E}^{[\mathrm{a}]}$} & 0.5939 & 0.5364 & 0.442 & 0.6364 & 0.6276 & 0.7191 & 0.7254 \\
\hline & [0.5995] & & & & & & \\
\hline \multirow[t]{2}{*}{$\% \Sigma r_{v d W}^{[a]}$} & 84 & 86 & 88 & 83 & 84 & 82 & 82 \\
\hline & [84] & & & & & & \\
\hline \multirow[t]{2}{*}{$\mathbf{X}(\mathbf{1})-\mathbf{C}(\mathbf{1})$} & $1.901(6)$ & $2.126(6)$ & $2.118(11)$ & $1.919(3)$ & $2.122(4)$ & $1.917(6)$ & $2.108(6)$ \\
\hline & {$[1.897(6)]$} & & & & & & \\
\hline \multirow[t]{2}{*}{$\mathbf{E}(\mathbf{1})-\mathbf{C}(\mathbf{9})$} & $1.770(6)$ & $1.773(6)$ & $1.765(11)$ & $1.948(3)$ & $1.958(4)$ & $2.153(6)$ & $2.151(6)$ \\
\hline & {$[1.778(6)]$} & & & & & & \\
\hline \multicolumn{8}{|c|}{ Naphthalene bond lengths } \\
\hline \multirow[t]{2}{*}{$\mathrm{C}(1)-\mathrm{C}(2)$} & $1.365(9)$ & $1.384(9)$ & $1.363(14)$ & $1.363(6)$ & 1.373(7) & $1.382(12)$ & $1.382(12)$ \\
\hline & [1.381(9)] & & & & & & \\
\hline \multirow[t]{2}{*}{$\mathbf{C}(2)-\mathrm{C}(3)$} & $1.403(10)$ & 1.391(10) & $1.406(15)$ & $1.402(5)$ & $1.402(7)$ & $1.387(11)$ & $1.389(10)$ \\
\hline & {$[1.391(9)]$} & & & & & & \\
\hline \multirow[t]{2}{*}{$\mathbf{C}(3)-\mathrm{C}(4)$} & $1.348(9)$ & $1.343(9)$ & $1.342(17)$ & $1.354(5)$ & $1.372(9)$ & $1.352(10)$ & $1.356(10)$ \\
\hline & {$[1.331(10)]$} & & & & & & \\
\hline \multirow[t]{2}{*}{$C(4)-C(5)$} & $1.395(9)$ & $1.409(9)$ & $1.467(19)$ & $1.436(6)$ & $1.418(7)$ & $1.417(12)$ & $1.400(11)$ \\
\hline & {$[1.417(10)]$} & & & & & & \\
\hline \multirow[t]{2}{*}{$\mathbf{C}(5)-C(10)$} & $1.446(8)$ & $1.435(8)$ & $1.414(17)$ & $1.433(5)$ & 1.449(6) & $1.440(9)$ & $1.454(8)$ \\
\hline & {$[1.441(8)]$} & & & & & & \\
\hline \multirow[t]{2}{*}{$C(5)-C(6)$} & $1.443(9)$ & $1.409(9)$ & $1.393(19)$ & $1.420(5)$ & $1.414(9)$ & $1.422(9)$ & 1.411(9) \\
\hline & {$[1.404(9)]$} & & & & & & \\
\hline \multirow[t]{2}{*}{$\mathbf{C}(6)-\mathbf{C}(7)$} & $1.312(9)$ & $1.348(11)$ & $1.358(19)$ & 1.373(6) & $1.372(8)$ & $1.399(13)$ & $1.379(12)$ \\
\hline & {$[1.376(10)]$} & & & & & & \\
\hline \multirow[t]{2}{*}{$\mathbf{C}(7)-\mathbf{C}(8)$} & $1.398(8)$ & $1.410(11)$ & $1.319(17)$ & $1.395(5)$ & 1.416(7) & $1.363(10)$ & $1.365(10)$ \\
\hline & {$[1.388(10)]$} & & & & & & \\
\hline \multirow[t]{2}{*}{$\mathbf{C}(\mathbf{8})-\mathbf{C}(\mathbf{9})$} & $1.371(9)$ & $1.387(10)$ & $1.425(16)$ & $1.384(5)$ & $1.366(8)$ & $1.384(9)$ & $1.346(9)$ \\
\hline & {$[1.382(9)]$} & & & & & & \\
\hline \multirow[t]{2}{*}{$\mathbf{C}(\mathbf{9})-\mathbf{C}(10)$} & $1.443(8)$ & $1.449(9)$ & $1.458(15)$ & $1.434(6)$ & $1.452(7)$ & $1.433(11)$ & $1.443(11)$ \\
\hline & [1.415(9)] & & & & & & \\
\hline \multirow[t]{2}{*}{$\mathbf{C}(10)-\mathbf{C}(1)$} & $1.419(8)$ & $1.439(9)$ & $1.441(15)$ & $1.431(5)$ & $1.437(8)$ & $1.419(9)$ & $1.418(9)$ \\
\hline & {$[1.433(9)]$} & & & & & & \\
\hline
\end{tabular}


Table 1 Continued - Selected interatomic distances $[\AA]$ and angles $\left[^{\circ}\right]$ for $\mathbf{1 , 2 , 4 - 8}$ [values in parentheses are for independent molecules]

\begin{tabular}{|c|c|c|c|c|c|c|c|}
\hline Compound & $\mathbf{1}^{[18]}$ & 2 & 4 & $5^{[21]}$ & 6 & 7 & 8 \\
\hline \multicolumn{8}{|l|}{ Peri-region bond angles } \\
\hline $\mathbf{X}(\mathbf{1})-\mathbf{C}(\mathbf{1})-\mathbf{C}(\mathbf{1 0})$ & $\begin{array}{c}124.5(4) \\
{[124.1(4)]}\end{array}$ & 127.1(4) & $127.2(8)$ & 122.1(3) & $124.2(3)$ & $121.7(6)$ & $123.4(5)$ \\
\hline $\mathbf{C}(1)-\mathbf{C}(10)-\mathbf{C}(\mathbf{9})$ & $\begin{array}{c}128.8(5) \\
{[128.1(5)]}\end{array}$ & $128.2(5)$ & $128.4(10)$ & 128.3(3) & $128.3(4)$ & $128.6(6)$ & $129.2(5)$ \\
\hline $\mathbf{E}(\mathbf{1})-\mathbf{C}(9)-\mathbf{C}(10)$ & $\begin{array}{c}121.2(4) \\
{[122.9(5)]}\end{array}$ & 121.6(4) & $125.2(8)$ & $122.6(2)$ & $122.4(4)$ & $123.3(4)$ & $123.6(4)$ \\
\hline$\Sigma$ of bay angles & $\begin{aligned} \Sigma & =374.5(9) \\
{[\Sigma} & =375.1(9)]\end{aligned}$ & $\Sigma=376.9(9)$ & $\Sigma=380.8(18)$ & $\Sigma=373.0(6)$ & $\Sigma=374.9(7)$ & $\Sigma=373.6(10)$ & $\Sigma=376.2(9)$ \\
\hline Splay angle ${ }^{[b]}$ & $\begin{array}{c}14.5 \\
{[15.1]}\end{array}$ & 16.9 & 20.8 & 13.0 & 14.9 & 13.6 & 16.2 \\
\hline $\mathbf{C}(4)-\mathbf{C}(5)-\mathbf{C}(6)$ & $\begin{array}{l}119.5(5) \\
118.9(5)\end{array}$ & $117.8(5)$ & $117.0(12)$ & $118.5(3)$ & $118.8(4)$ & $118.9(6)$ & $118.9(6)$ \\
\hline $\mathbf{X}(\mathbf{1})-\mathbf{E}(\mathbf{1})-\mathbf{C}(\mathbf{1 1})$ & $\begin{array}{c}169.7(1) \\
{[169.8(1)]}\end{array}$ & 167.3(1) & $85.8(1)$ & $175.7(1)$ & 174.3(1) & 173.1(1) & $175.1(1)$ \\
\hline \multicolumn{8}{|c|}{ Out-of-plane displacement } \\
\hline $\mathbf{X}(\mathbf{1})$ & $\begin{array}{l}-0.14(1) \\
{[0.01(1)]}\end{array}$ & $0.36(1)$ & $-0.072(1)$ & $0.40(1)$ & $0.50(1)$ & $0.4058(84)$ & $-0.4152(86)$ \\
\hline $\mathbf{E}(\mathbf{1})$ & $\begin{array}{c}0.04(1) \\
{[-0.04(1)]} \\
\end{array}$ & $-0.17(1)$ & $0.049(1)$ & $-0.42(1)$ & $-0.42(1)$ & $-0.529(88)$ & $0.5355(86)$ \\
\hline \multicolumn{8}{|c|}{ Central naphthalene ring torsion angles } \\
\hline C:(6)-(5)-(10)-(1) & $\begin{array}{l}-179.2(5) \\
{[179.2(5)]}\end{array}$ & $-177.0(5)$ & $176.9(10)$ & $175.8(3)$ & 174.9(5) & $174.8(6)$ & $-174.5(6)$ \\
\hline C:(4)-(5)-(10)-(9) & $\begin{array}{l}-178.4(6) \\
{[179.1(5)]}\end{array}$ & $-177.9(5)$ & $-178.3(9)$ & 173.8(3) & 174.6(5) & 173.4(6) & $-175.1(6)$ \\
\hline
\end{tabular}

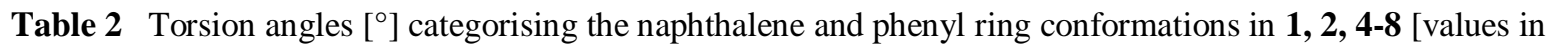
parentheses are for independent molecules]

\begin{tabular}{|c|c|c|c|c|}
\hline \multirow[t]{2}{*}{ Compound } & \multicolumn{2}{|c|}{ Naphthalene ring conformations } & \multicolumn{2}{|l|}{ Phenyl ring conformations } \\
\hline & $\mathrm{C}(10)-\mathrm{C}(9)-\mathrm{E}(1)-\mathrm{C}(11)$ & Conformation & $\mathrm{C}(9)-\mathrm{E}(1)-\mathrm{C}(11)-\mathrm{C}(12)$ & Conformation \\
\hline 1 & $\theta-177.2(5)[177.4(5)]$ & Nap: $^{[\mathrm{a}]}$ equatorial $^{[\mathrm{d}]}$ & $(\gamma 175.2(4)[-179.9(4)])$ & (Et: equatorial) \\
\hline 2 & $\theta-174.3(5)$ & Nap: equatorial & $(\gamma 176.4(5))$ & (Et: equatorial) \\
\hline 4 & $\theta 83.6(10)$ & Nap: axial ${ }^{[\mathrm{c}]}$ & $\gamma 1.4(10)$ & $\mathrm{Ph}:^{[\mathrm{b}]}$ equatorial \\
\hline 5 & $\theta-159.2(3)$ & Nap: equatorial & $\gamma-96.0(3)$ & Ph: axial \\
\hline 6 & $\theta-157.0(4)$ & Nap: equatorial & $\gamma-89.4(4)$ & $\mathrm{Ph}$ : axial \\
\hline 7 & $\theta-160.0(6)$ & Nap: equatorial & $\gamma-99.4(5)$ & $\mathrm{Ph}$ : axial \\
\hline 8 & $\theta-158.1(6)$ & Nap: equatorial & $\gamma-86.5(5)$ & Ph: axial \\
\hline
\end{tabular}


${ }^{[a]}$ Nap: naphthalene ring E(1); ${ }^{[b]} \mathbf{P h}$ : E(1) phenyl ring; ${ }^{[c]}$ axial: perpendicular to C(ar)-E-C(ar) plane; ${ }^{[d]}$ equatorial: coplanar with $\mathrm{C}(\operatorname{ar})-\mathrm{E}-\mathrm{C}(\mathrm{ar})$ plane.

Table 3 Results of ab initio MO Calculations performed on 5-8 evaluated at the B3LYP/6-31+G* level using X-ray and fully optimised geometries.

\begin{tabular}{lllll}
\hline X...Y Expt. & (WBI) & X...Y Calc. & (WBI) \\
\hline $\mathbf{8}$ & 3.114 & 0.05 & 3.172 & 0.05 \\
\hline $\mathbf{8}$ & 3.252 & 0.06 & 3.336 & 0.05 \\
\hline
\end{tabular}

Table 4 Crystallographic data for compounds 2 and 4

\begin{tabular}{|c|c|c|}
\hline Compound & 2 & 4 \\
\hline Empirical Formula & $\mathrm{C}_{12} \mathrm{H}_{11} \mathrm{IS}$ & $\mathrm{C}_{16} \mathrm{H}_{11} \mathrm{IS}$ \\
\hline Formula Weight & 314.18 & 362.21 \\
\hline Temperature $\left({ }^{\circ} \mathbf{C}\right)$ & $-148(1)$ & $20(1)$ \\
\hline Crystal Colour, Habit & colourless, prism & colourless, platelet \\
\hline Crystal Dimensions $\left(\mathrm{mm}^{3}\right)$ & $0.21 \times 0.09 \times 0.06$ & $0.10 \times 0.10 \times 0.10$ \\
\hline Crystal System & orthorhombic & orthorhombic \\
\hline \multirow[t]{6}{*}{ Lattice Parameters } & $a=7.768(2) \AA$ & $a=10.204(4) \AA$ \\
\hline & $\mathrm{b}=20.971(6) \AA$ & $\mathrm{b}=7.992(3) \AA$ \\
\hline & $c=13.735(4) \AA$ & $\mathrm{c}=32.888(10) \AA$ \\
\hline & - & - \\
\hline & - & - \\
\hline & - & - \\
\hline Volume $\left(\AA^{3}\right)$ & $\mathrm{V}=2237.5(12)$ & $\mathrm{V}=2682.0(17)$ \\
\hline Space Group & Pbca & Pbca \\
\hline$Z$ value & 8 & 8 \\
\hline Dcalc $\left(\mathrm{g} / \mathrm{cm}^{3}\right)$ & 1.865 & 1.794 \\
\hline F000 & 1216 & 1408 \\
\hline $\mathbf{m}($ MoKa $)\left(\mathrm{cm}^{-1}\right)$ & 30.068 & 2.521 \\
\hline No. of Reflections Measured & 6575 & 14054 \\
\hline Rint & 0.033 & 0.2862 \\
\hline Min and Max Transmissions & $0.504-0.835$ & $0.7461-1.000$ \\
\hline Independent Reflections & 1953 & 2440 \\
\hline
\end{tabular}




\begin{tabular}{lcc}
\hline Observed Reflection (No. Variables ) & $1824(128)$ & $1526(165)$ \\
Reflection/Parameter Ratio & 15.26 & 14.79 \\
Residuals: $\mathbf{R}_{\mathbf{1}}(\mathbf{I}>\mathbf{2 . 0 0 s}(\mathbf{I}))$ & 0.0435 & 0.0999 \\
Residuals: R (All reflections) & 0.056 & 0.1347 \\
Residuals: wR (All reflections) & 0.2054 & 0.2692 \\
Goodness of Fit Indicator & 1.285 & 0.975 \\
Flack Parameter & - & - \\
Maximum peak in Final Diff. Map & $2.18 \mathrm{e}-/ \AA^{3}$ & $2.198 \mathrm{e}-/ \AA^{3}$ \\
Minimum peak in Final Diff. Map & $-2.50 \mathrm{e}-/ \AA^{3}$ & $-1.651 \mathrm{e}-/ \AA^{3}$ \\
\hline
\end{tabular}

Table 4 Continued - Crystallographic data for compounds 6-8

\begin{tabular}{|c|c|c|c|}
\hline Compound & 6 & 7 & 8 \\
\hline Empirical Formula & $\mathrm{C}_{16} \mathrm{H}_{11} \mathrm{ISe}$ & $\mathrm{C}_{16} \mathrm{H}_{11} \mathrm{BrTe}$ & $\mathrm{C}_{16} \mathrm{H}_{11} \mathrm{ITe}$ \\
\hline Formula Weight & 409.13 & 410.77 & 457.77 \\
\hline Temperature $\left({ }^{\circ} \mathbf{C}\right)$ & $-148(1)$ & $-148(1)$ & $-148(1)$ \\
\hline Crystal Colour, Habit & colourless, prism & colourless, prism & colourless, prism \\
\hline Crystal Dimensions $\left(\mathrm{mm}^{3}\right)$ & $0.30 \times 0.24 \times 0.12$ & $0.09 \times 0.06 \times 0.06$ & $0.15 \times 0.09 \times 0.09$ \\
\hline Crystal System & triclinic & monoclinic & monoclinic \\
\hline \multirow[t]{6}{*}{ Lattice Parameters } & $\mathrm{a}=7.8388(7) \AA$ & $\mathrm{a}=12.556(3) \AA$ & $\mathrm{a}=12.437(8) \AA$ \\
\hline & $\mathrm{b}=8.1008(7) \AA$ & $\mathrm{b}=8.0136(16) \AA$ & $\mathrm{b}=8.174(4) \AA$ \\
\hline & $c=11.9491(10) \AA$ & $\mathrm{c}=14.803(4) \AA$ & $\mathrm{c}=14.694(10) \AA$ \\
\hline & $\alpha=98.5504(19)^{\circ}$ & - & - \\
\hline & $\beta=108.8828(18)^{\circ}$ & $\beta=111.945(4)^{\circ}$ & $\beta=110.305(14)^{\circ}$ \\
\hline & $\gamma=98.007(2)^{\circ}$ & - & - \\
\hline Volume $\left(\AA^{3}\right)$ & $V=695.57(10)$ & $\mathrm{V}=1381.5(6)$ & $V=1400.9(15)$ \\
\hline Space Group & $\mathrm{P}-1$ & $\mathrm{P} 2_{1} / \mathrm{c}$ & $\mathrm{P} 2_{1} / \mathrm{c}$ \\
\hline$Z$ value & 2 & 4 & 4 \\
\hline Dealc $\left(\mathrm{g} / \mathrm{cm}^{3}\right)$ & 1.953 & 1.975 & 2.17 \\
\hline F000 & 388 & 776 & 848 \\
\hline $\mathbf{m}(\mathbf{M o K a})\left(\mathrm{cm}^{-1}\right)$ & 48.984 & 50.327 & 43.072 \\
\hline No. of Reflections Measured & 6026 & 8205 & 9065 \\
\hline Rint & 0.072 & 0.039 & 0.032 \\
\hline Min and Max Transmissions & $0.257-0.556$ & $0.611-0.739$ & $0.470-0.679$ \\
\hline Independent Reflections & 2455 & 2759 & 2814 \\
\hline Observed Reflection (No. Variables ) & $2138(164)$ & $2579(164)$ & $2695(164)$ \\
\hline Reflection/Parameter Ratio & 14.97 & 16.82 & 17.16 \\
\hline Residuals: $\mathbf{R}_{\mathbf{1}}(\mathrm{I}>\mathbf{2 . 0 0 s}(\mathrm{I}))$ & 0.0445 & 0.0483 & 0.0356 \\
\hline Residuals: R (All reflections) & 0.0522 & 0.0572 & 0.0408 \\
\hline Residuals: $\mathbf{w R}_{\mathbf{2}}$ (All reflections) & 0.1063 & 0.149 & 0.1465 \\
\hline Goodness of Fit Indicator & 1.094 & 1.212 & 1.263 \\
\hline Flack Parameter & - & - & - \\
\hline Maximum peak in Final Diff. Map & $0.77 \mathrm{e}-/ \AA^{3}$ & $1.50 \mathrm{e}-/ \AA^{3}$ & $1.41 \mathrm{e}-/ \AA^{3}$ \\
\hline Minimum peak in Final Diff. Map & $-0.86 \mathrm{e}-/ \AA^{3}$ & $-1.69 \mathrm{e}-1 \AA^{3}$ & $-1.72 \mathrm{e}-/ \AA^{3}$ \\
\hline
\end{tabular}


